\title{
Discovery of fifteen new geroprotective plant extracts and identification of cellular processes they affect to prolong the chronological lifespan of budding yeast
}

\author{
Pamela Dakik ${ }^{1}$, Monica Enith Lozano Rodriguez ${ }^{1}$, Jennifer Anne Baratang Junio ${ }^{1}$, Darya \\ Mitrofanova $^{1}$, Younes Medkour ${ }^{1}$, Tala Tafakori ${ }^{1}$, Tarek Taifour ${ }^{1}$, Vicky Lutchman ${ }^{1}$, \\ Eugenie Samson ${ }^{1}$, Anthony Arlia-Ciommo ${ }^{1}$, Belise Rukundo ${ }^{1}$, Éric Simard ${ }^{2}$ and Vladimir \\ I. Titorenko ${ }^{1}$ \\ ${ }^{1}$ Department of Biology, Concordia University, Montreal, Quebec H4B 1R6, Canada \\ ${ }^{2}$ Idunn Technologies Inc., Rosemere, Quebec J7A 4A5, Canada \\ Correspondence to: Vladimir I. Titorenko, email: vladimir.titorenko@concordia.ca \\ Keywords: cellular aging; longevity; gerotargets; geroprotectors; plant extracts \\ Received: April 01, $2020 \quad$ Accepted: May 14, $2020 \quad$ Published: June 09, 2020 \\ Copyright: Dakik et al. This is an open-access article distributed under the terms of the Creative Commons Attribution License 3.0 (CC BY \\ 3.0 ), which permits unrestricted use, distribution, and reproduction in any medium, provided the original author and source are credited.
}

\section{ABSTRACT}

In a quest for previously unknown geroprotective natural chemicals, we used a robust cell viability assay to search for commercially available plant extracts that can substantially prolong the chronological lifespan of budding yeast. Many of these plant extracts have been used in traditional Chinese and other herbal medicines or the Mediterranean and other customary diets. Our search led to a discovery of fifteen plant extracts that significantly extend the longevity of chronologically aging yeast not limited in calorie supply. We show that each of these longevity-extending plant extracts is a geroprotector that decreases the rate of yeast chronological aging and promotes a hormetic stress response. We also show that each of the fifteen geroprotective plant extracts mimics the longevity-extending, stress-protecting, metabolic and physiological effects of a caloric restriction diet but if added to yeast cultured under non-caloric restriction conditions. We provide evidence that the fifteen geroprotective plant extracts exhibit partially overlapping effects on a distinct set of longevity-defining cellular processes. These effects include a rise in coupled mitochondrial respiration, an altered age-related chronology of changes in reactive oxygen species abundance, protection of cellular macromolecules from oxidative damage, and an age-related increase in the resistance to long-term oxidative and thermal stresses.

\section{INTRODUCTION}

The budding yeast Saccharomyces cerevisiae is a widely used model organism in aging research because it offers three significant advantages in studying mechanisms of aging and longevity [1-5]. First, $S$. cerevisiae has relatively short and easily measurable replicative and chronological lifespans. Second, the $S$. cerevisiae genome has been completely sequenced and many strain collections for yeast genome interrogation are commercially available. Third, S. cerevisiae is amenable to comprehensive molecular analyses that have been used to uncover mechanisms of various cell biological processes
[4, 6-10]. Because of these advantages, studies in $S$. cerevisiae discovered many genes, signaling pathways and chemical compounds that, following their discovery in budding yeast, were implicated in aging and longevity in organisms across an evolutionary tree [4, 5, 8, 11-15]. It is therefore commonly believed that the major aspects and underlying mechanisms of aging and aging-associated pathology have been conserved throughout evolution $[8$, 14-32].

Our research aims to understand mechanisms through which certain chemical compounds of plant origin act as geroprotectors capable of delaying chronological aging and postponing aging-associated pathology in 
budding yeast. Our recent screen of a collection of thirty-five plant extracts (PEs) had identified six PEs that can prolong chronological lifespan (CLS) and delay chronological aging in S. cerevisiae [33]. We found that in $S$. cerevisiae, the six PEs exhibit different effects on cellular processes known to define longevity in eukaryotes across species [33]. These effects of the six aging-delaying PEs included an increase in mitochondrial respiration and membrane potential, a moderate but significant rise or decline in cellular reactive oxygen species (ROS), a weakening of oxidative damage to cellular proteins, lipids and DNA, an augmentation of cell resistance to long-term oxidative and thermal stresses, and an enhancement of neutral lipid lipolysis in lipid droplets [33]. We also revealed that the six PEs extend yeast CLS through different signaling pathways and protein kinases converged into a network; this network is known to define the rate of chronological aging in $S$. cerevisiae and to regulate longevity in other eukaryotic organisms [34]. The network integrates the pro-aging TORC1 (target of rapamycin complex 1) pathway, the pro-aging PKA (protein kinase A) pathway, the pro-aging PKH1/2 (Pkb-activating kinase homolog) pathway, the antiaging SNF1 (sucrose non-fermenting) pathway, the antiaging ATG (autophagy) pathway, the pro-aging serine/ threonine-protein kinase Sch9 and the anti-aging serine/ threonine-protein kinase Rim15 (regulator of IME2) [34]. We provided evidence that pairwise combinations of the six PEs display synergistic effects on the delay of yeast chronological aging only if each of the PEs comprising a combination targets a different signaling pathway or protein kinase of longevity regulation [35]. Moreover, we described three different mechanisms through which one of the six PEs, which is called PE21, can delay yeast chronological aging and extend yeast longevity [36].

The objective of the present study was to search for previously unknown aging-delaying (geroprotective) PEs. To attain this objective, we conducted a new screen of many extracts from plants used in traditional Chinese and other herbal medicines or the Mediterranean and other diets. Our screen discovered fifteen new geroprotective PEs that extend yeast CLS. We show that each of these new aging-delaying PEs decreases the rate of yeast chronological aging, stimulates a hormetic stress response and regulates a distinct set of longevity-defining cellular processes.

\section{RESULTS}

\section{Identification of new PEs that prolong the longevity of chronologically aging budding yeast}

In search of new geroprotective PEs, we performed a screen of fifty-three commercially available PEs. The origin and properties of these PEs are shown in Supplementary Table 1. These PEs are believed to have positive effects on human health, and many of them have been used in traditional Chinese and other herbal medicines or the Mediterranean and other long-established diets.

To conduct the screen, we exploited a robust clonogenic cell viability assay for measuring yeast CLS [33]. In this assay, the wild-type (WT) strain BY4742 was cultured in the synthetic minimal YNB medium initially containing $2 \%(\mathrm{w} / \mathrm{v})$ glucose, as described in Materials and Methods. Cells of budding yeast cultured under such non-caloric restriction (non-CR) conditions are known to age chronologically faster than the ones cultured under CR conditions on $0.2 \%(\mathrm{w} / \mathrm{v})$ or $0.5 \%(\mathrm{w} / \mathrm{v})$ glucose $[1,3,4,33]$.

At the time of cell inoculation into the culturing medium, we added each of the assessed PEs at a final concentration ranging from $0.02 \%(\mathrm{w} / \mathrm{v})$ to $1.0 \%(\mathrm{w} / \mathrm{v})$. We found that PE40, PE41, PE44, PE50, PE53, PE66, PE73, PE84, PE86 and PE87 do not affect the mean and maximum CLS of WT yeast if exogenously supplemented within this wide range of initial concentrations (Supplementary Figures 1-7). In contrast, PE38, PE43, PE45, PE46, PE48, PE49, PE51, PE52, PE54-PE58, PE60-PE63, PE65, PE67, PE70, PE71, PE74, PE76, PE80, PE82, PE85, PE88 and PE89 were cytotoxic at certain concentrations; they decreased the mean and/or maximum CLS of WT yeast if used at the final concentrations in the $0.1(\mathrm{w} / \mathrm{v})$ to $1.0 \%$ $(\mathrm{w} / \mathrm{v})$ range (Supplementary Figures 1-7).

Our screen revealed that fifteen of fifty-three tested PEs statistically significantly increase the mean and maximum CLS of WT yeast cultured under nonCR conditions on 2\%(w/v) glucose (Figures 1 and 2; Supplementary Figures 1-6). Each of these fifteen PEs extended the longevity of chronologically aging WT yeast if used within a specific concentration range and exhibited the highest longevity-extending effect at a certain concentration within this range (Supplementary Figures 1-6). The following PEs exhibited the highest longevity-extending effect under non-CR conditions of cell culturing: 0.5\% (w/v) PE26 from berries of Serenoa repens (Figure 1A, Supplementary Figure 1), 0.5\% (w/v) PE39 from aerial parts of Hypericum perforatum (Figure 1B, Supplementary Figure 1), 0.5\% (w/v) PE42 from leaves of Ilex paraguariensis (Figure 1C, Supplementary Figure 1), 0.3\% (w/v) PE47 from leaves of Ocimum tenuiflorum (Figure 1D, Supplementary Figure 2), 0.3\% (w/v) PE59 from the whole plant of Solidago virgaurea (Figure 1E, Supplementary Figure 3), 0.1\% (w/v) PE64 from fruits of Citrus sinensis (Figure 1F, Supplementary Figure 4), 0.5\% (w/v) PE68 from the whole plant of Humulus lupulus (Figure 1G, Supplementary Figure 4), $1.0 \%(\mathrm{w} / \mathrm{v})$ PE69 from grape skins of Vitis vinifera (Figure 1H, Supplementary Figure 5), 0.1\% (w/v) PE72 from the whole plant of Andrographis paniculata (Figure 2A, Supplementary Figure 5), 0.3\% (w/v) PE75 from roots of Hydrastis canadensis (Figure 2B, Supplementary Figure 5), 0.5\% (w/v) PE77 from seeds of Trigonella foenum-graecum (Figure 2C, Supplementary Figure 6), 
0.3\% (w/v) PE78 from root barks of Berberis vulgaris (Figure 2D, Supplementary Figure 6), 0.5\% (w/v) PE79 from leaves, flowers and stems of Crataegus monogyna (Figure 2E, Supplementary Figure 6), 0.3\% (w/v) PE81 from leaves of Taraxacum erythrospermum (Figure 2F, Supplementary Figure 6), and 0.5\% (w/v) PE83 from the whole plant of of Ilex paraguariensis (Figure 2G, Supplementary Figure 6).

We found that none of the fifteen longevityextending PEs displays a statistically significant effect on glucose consumption during culturing of WT cells under non-CR conditions on 2\% (w/v) glucose (Supplementary Figure 8). This finding shows that each of these PEs prolongs the longevity of chronologically aging yeast not because it alters the concentration of exogenous glucose and, thus, not because it affects the metabolic rate of this major source of carbon and energy. We also found that none of the fifteen longevity-extending PEs exhibits a statistically significant effect on the growth rate and maximum cell yield of WT yeast cultures under
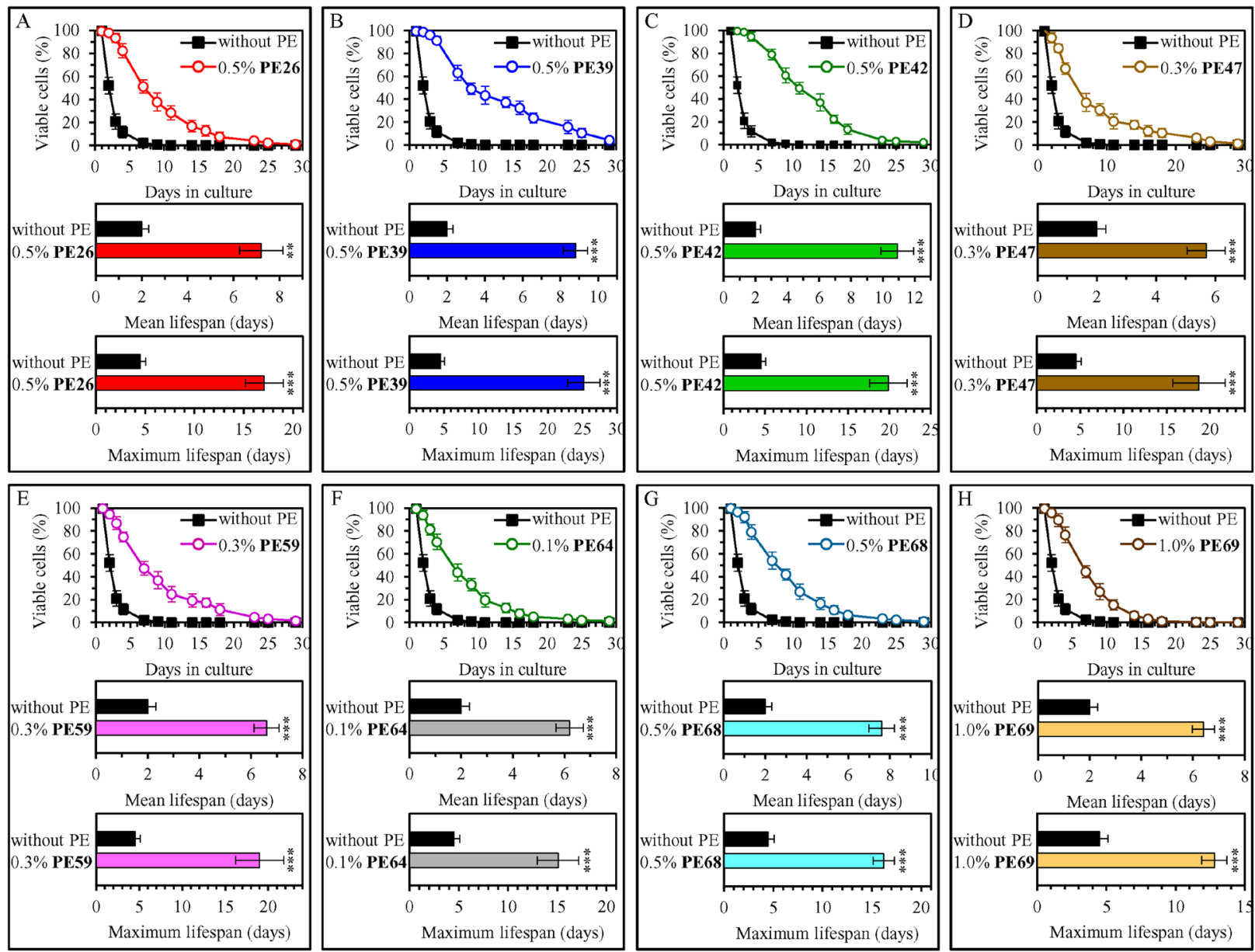

Figure 1: 0.5\% (w/v) PE26, 0.5\% (w/v) PE39, 0.5\% (w/v) PE42, 0.3\% (w/v) PE47, 0.3\% (w/v) PE59, 0.1\% (w/v) PE64, $0.5 \%$ (w/v) PE68 and $1.0 \%$ (w/v) PE69 exhibit the highest extending effects on the chronological lifespan (CLS) of wild-type (WT) yeast cultured under non-CR conditions on $2 \%(w / v)$ glucose. WT cells were cultured in the synthetic minimal YNB medium initially containing $2 \%(\mathrm{w} / \mathrm{v})$ glucose, in the presence of a PE or its absence. In the cultures supplemented with a PE, ethanol was used as a vehicle at a final concentration of $2.5 \%(\mathrm{v} / \mathrm{v})$. In the same experiment, WT cells were also subjected to ethanol-mock treatment by being cultured in the synthetic minimal YNB medium initially containing $2 \%(\mathrm{w} / \mathrm{v})$ glucose and $2.5 \%(\mathrm{v} / \mathrm{v})$ ethanol. Survival curves (the upper panels in $\mathbf{A}-\mathbf{H}$ ) and the mean and maximum lifespans (the lower two panels in A-H) of chronologically aging WT cells cultured without a PE (cells were subjected to ethanol-mock treatment) or with a PE (which was added at the concentration optimal for CLS extension) are shown. Data are presented as means $\pm \operatorname{SEM}(n=6)$. In the upper panels in $\mathrm{A}-\mathrm{H}, \mathrm{CLS}$ extension was significant for each of the PEs tested $(p<0.05$; the $p$ values for comparing each pair of survival curves were calculated using the logrank test as described in Materials and Methods). In the lower two panels in $\mathrm{A}-\mathrm{H},{ }^{*} p<0.05,{ }^{* *} p<0.01,{ }^{* * *} p<0.001$; the $p$ values for comparing the means of two in groups were calculated using an unpaired two-tailed $t$ test as described in Materials and Methods). Data for mock-treated WT cells are replicated in graphs A-H of this Figure, graphs A-G of Figure 2 and Supplementary Figures 1-7. Data for WT cells cultured with a PE added at the concentration optimal for CLS extension are replicated in Supplementary Figure 1 (for 0.5\% (w/v) PE26, 0.5\% (w/v) PE39 and 0.5\% (w/v) PE42), Supplementary Figure 2 (for $0.3 \%$ (w/v) PE47), Supplementary Figure 3 (for $0.3 \%$ (w/v) PE59), Supplementary Figure 4 (for $0.1 \%$ $(\mathrm{w} / \mathrm{v})$ PE64 and 0.5\% (w/v) PE68) and Supplementary Figure 5 (for 1.0\% (w/v) PE69). 
non-CR conditions (Supplementary Figure 9). Based on this observation, we concluded that each of them extends the longevity of chronologically aging yeast not because it slows cell proliferation and, thus, not because it desensitizes yeast to harmful chemical compounds produced when cells proliferate.

\section{Each of the fifteen longevity-prolonging PEs mimics longevity extension by $C R$}

$\mathrm{CR}$ without malnutrition is a low-calorie dietary regimen that extends lifespan in many evolutionarily distant organisms and improves healthspan in laboratory rodents and rhesus monkeys [4, 8, 37-39]. Certain natural chemicals and synthetic drugs have been shown to elicit the CR-like lifespan-extending and healthspan-improving effects even under non-CR conditions (i. e., when calorie supply is not limited) [40-45]. These natural and synthetic chemical compounds are called CR mimetics (CRMs) if they not only extend longevity under non-CR conditions but also if they exhibit three other effects. First, CRMs do not impair food intake. Second, CRMs have CR-like effects on metabolism and physiology. Third, akin to CR, CRMs decrease the susceptibility to diverse stresses
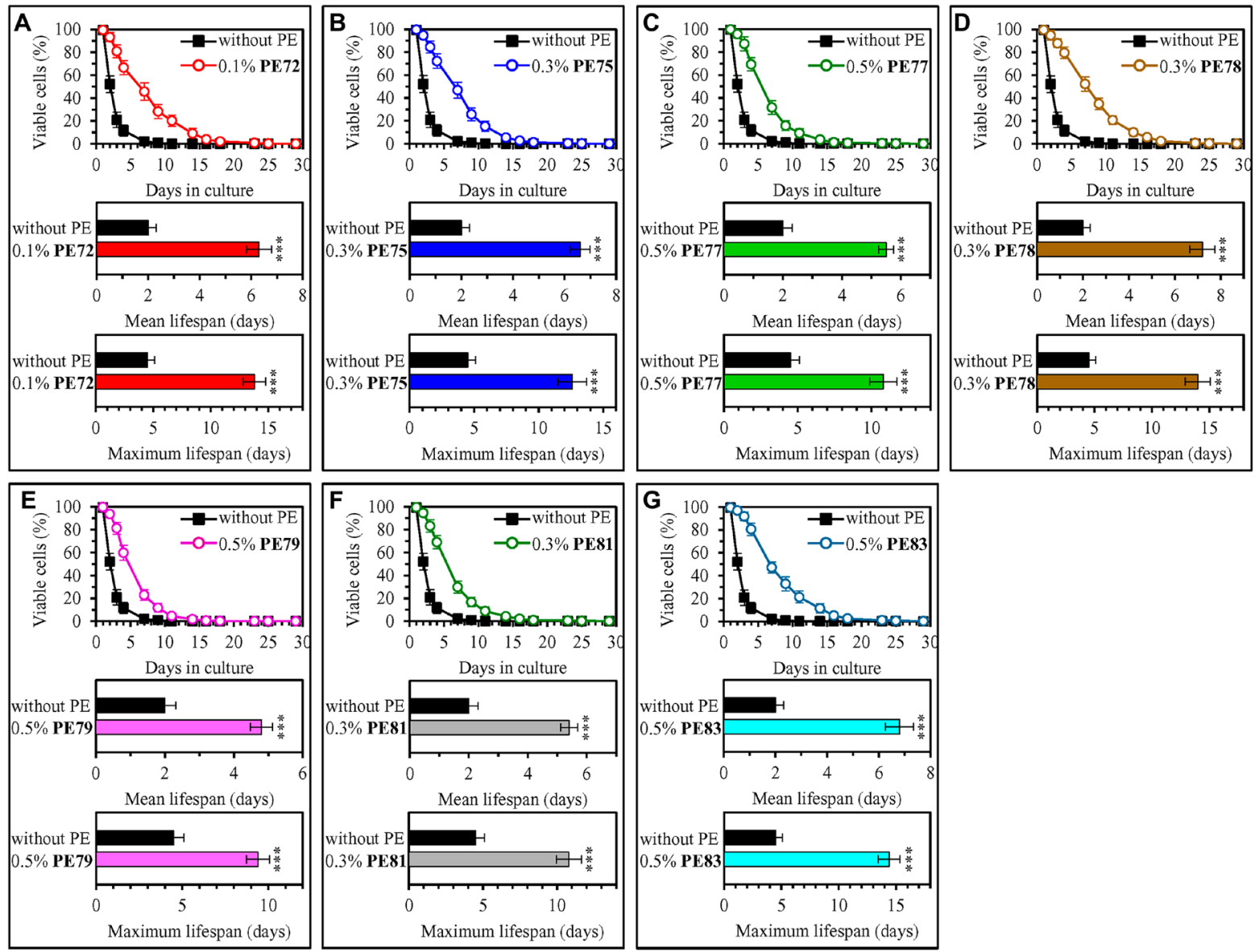

Figure 2: 0.1\% (w/v) PE72, 0.3\% (w/v) PE75, 0.5\% (w/v) PE77, 0.3\% (w/v) PE78, 0.5\% (w/v) PE79, 0.3\% (w/v) PE81

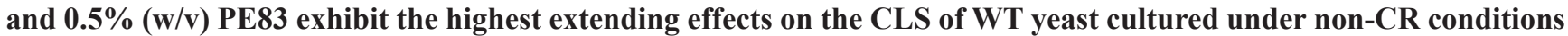
on $2 \%(w / v)$ glucose. WT cells were cultured in the synthetic minimal YNB medium initially containing $2 \%(w / v)$ glucose, in the presence of a PE or its absence. In the cultures supplemented with a PE, ethanol was used as a vehicle at a final concentration of $2.5 \%(\mathrm{v} / \mathrm{v})$. In the same experiment, WT cells were also subjected to ethanol-mock treatment by being cultured in the synthetic minimal YNB medium initially containing $2 \%(\mathrm{w} / \mathrm{v})$ glucose and $2.5 \%(\mathrm{v} / \mathrm{v})$ ethanol. Survival curves (the upper panels in $\mathbf{A}-\mathbf{G})$ and the mean and maximum lifespans (the lower two panels in A-G) of chronologically aging WT cells cultured without a PE (cells were subjected to ethanol-mock treatment) or with a PE (which was added at the concentration optimal for CLS extension) are shown. Data are presented as means \pm SEM $(n=6)$. In the upper panels in A-G, CLS extension was significant for each of the PEs tested $(p<0.05$; the $p$ values for comparing each pair of survival curves were calculated using the logrank test as described in Materials and Methods). In the lower two panels in A-G, ${ }^{*} p<$ $0.05,{ }^{* * *} p<0.01,{ }^{* * *} p<0.001$; the $p$ values for comparing the means of two in groups were calculated using an unpaired two-tailed $t$ test as described in Materials and Methods). Data for mock-treated WT cells are replicated in graphs A-G of this Figure, graphs A-H of Figure 1 and Supplementary Figures 1-7. Data for WT cells cultured with a PE added at the concentration optimal for CLS extension are replicated in Supplementary Figure 4 (for $0.1 \%(w / v)$ PE72 and $0.3 \%(w / v)$ PE75) and Supplementary Figure 6 (for $0.5 \%(w / v)$ PE77, 0.3\% (w/v) PE78, 0.5\% (w/v) PE79, 0.3\% (w/v) PE81 and 0.5\% (w/v) PE83). 
$[41,44]$. In the present study we found that each of the fifteen longevity-extending PEs increases yeast CLS under non-CR conditions on 2\% (w/v) glucose (Figures 1 and 2; Supplementary Figures 1-6) and none of them compromises glucose intake during culturing under these conditions (Supplementary Figure 8). Thus, it seems that all these PEs are CRMs. This conclusion is further supported by our observations that each of the fifteen longevity-extending PEs exhibits CR-like effects on several aspects of cell metabolism and stress resistance (see below).

Of note, we previously reported that if the CR diet is administered by culturing yeast in the YNB medium initially containing $0.5 \%(\mathrm{w} / \mathrm{v})$ glucose, it significantly increases both the mean and maximum CLS of $S$. cerevisiae [33]. In the present study, we investigated how each of the fifteen PEs that extends longevity under non-CR conditions influences the longevity of yeast cultured under CR conditions on $0.5 \%(\mathrm{w} / \mathrm{v})$ glucose. We found that eight of the fifteen PEs that prolong the longevity of chronologically aging yeast under non-CR conditions do not increase either the mean or the maximum CLS of $S$. cerevisiae under CR conditions (Supplementary Figures 10 and 11). These PEs included 0.3\% (w/v) PE47 (Supplementary Figure 10D), 0.1\% (w/v) PE64 (Supplementary Figure $10 \mathrm{~F}), 1.0 \%$ (w/v) PE69 (Supplementary Figure 10H), $0.1 \%$ (w/v) PE72 (Supplementary Figure 11A), 0.3\% $(w / v)$ PE75 (Supplementary Figure 11B), 0.5\% (w/v) PE77 (Supplementary Figure 11C), 0.5\% (w/v) PE79 (Supplementary Figure 11E) and $0.3 \%(\mathrm{w} / \mathrm{v})$ PE81 (Supplementary Figure 11F). It seems conceivable, therefore, that each of these eight PEs increases yeast CLS because it modulates the same or highly overlapping sets of longevity-defining cellular processes under both $\mathrm{CR}$ and non-CR conditions. Some of these processes can be suppressed under non-CR conditions, whereas others can operate as cellular housekeeping processes that are not regulated in a CR-dependent manner. The relative contributions of the CR-regulated and housekeeping (i. e., not regulated by $\mathrm{CR}$ ) cellular processes to the process of yeast chronological aging need to be addressed in the future.

We also revealed that seven of the fifteen PEs that extend yeast longevity under non-CR conditions also increase both the mean and maximum CLS of $S$. cerevisiae under CR conditions (Supplementary Figures 10 and 11 ). 0.5\% (w/v) PE26 (Supplementary Figure $10 \mathrm{~A}), 0.5 \%$ (w/v) PE39 (Supplementary Figure 10B), $0.5 \%$ (w/v) PE42 (Supplementary Figure 10C), 0.3\% $(w / v)$ PE59 (Supplementary Figure 10E), 0.5\% (w/v) PE68 (Supplementary Figure 10G), 0.3\% (w/v) PE78 (Supplementary Figure 11D) and $0.5 \%(\mathrm{w} / \mathrm{v})$ PE83 (Supplementary Figure 11G) were among these PEs. Therefore, we hypothesize that each of these seven PEs increases yeast CLS under both CR and non-CR conditions because it targets both CR-regulated and housekeeping (i.e., not regulated by $\mathrm{CR}$ ) cellular processes.

We then compared the efficiency with which each of the fifteen PEs increases yeast CLS under non-CR conditions to that under $\mathrm{CR}$ conditions. Our comparison revealed that each of these PEs extends the longevity of chronologically aging yeast under non-CR conditions significantly more efficiently than it does under CR conditions (Figure 3). This finding shows that each of the fifteen PEs is a more effective longevity-prolonging intervention in chronologically aging yeast not-limited in calorie supply than it is in yeast placed on a CR diet.

\section{Each of the fifteen longevity-prolonging PEs is a geroprotector that extends the longevity of chronologically aging yeast because it decreases the rate of aging and stimulates a hormetic stress response}

The rate of biological aging at the demographic level depends on the health of a population and can be determined by measuring an age-specific mortality rate of this population [46-50]. The mortality rates of evolutionarily distant organisms rise with age [46, 48-51]. The Gompertz mortality function equation can describe this age-related rise in the mortality rate; this equation can be graphically presented as mortality rate data plotted on a semi-log scale against biological age [46, 48, 50-52]. Geroprotective interventions (also known as geroprotectors) can extend the longevity of organisms across phyla by causing three different effects on the Gompertz mortality function. Some geroprotectors can lower a so-called "baseline" mortality rate by eliciting an equal decline in the mortality rate at any biological age, without affecting a slope of the Gompertz mortality rate $[47,48,50,53,54]$. This slope is known as the coefficient $G$ of the age-specific mortality rate; it is inversely proportional to the rate of biological aging [47, $48,50,53,54]$. Other geroprotectors can decrease the rate of biological aging because they lower the value of $G$, thus raising the value of the mortality rate doubling time (MRDT; MRDT $=0.693 / G)[47,48,50,55,56]$. The longevity-extending effects of some other geroprotective interventions can represent a combination of both the drop in the baseline mortality rate and the decline in the value of $G$ (which raises the value of MRDT) [46-48, 50, 54].

We sought to investigate whether each of the fifteen PEs extends yeast longevity by lowering the baseline mortality rate, decreasing the rate of biological aging or by altering both these rates. Therefore, we conducted the Gompertz mortality rate analysis of WT cells under non-CR conditions that were either treated with one of these PEs or subjected to mock treatment. We found the following: 1) none of the fifteen longevity-prolonging PEs affects the baseline mortality rate, and 2) each of them elicits a decline in the coefficient $G$ of the age-specific 
mortality rate and causes a rise in the value of MRDT (Figure 4). Based on these observations, we concluded that each of these PEs is a geroprotector that lengthens the longevity of chronologically aging yeast because it lowers the rate of aging but not because it decreases the baseline mortality rate.

Our data allow us to conclude that each of the fifteen longevity-prolonging PEs slows yeast chronological aging because it decreases both the extrinsic and the intrinsic rates of aging. This conclusion is based on our findings that each of these PEs extends both the mean and maximum CLS of yeast (Figures 1 and 2). The mean lifespans of evolutionarily distant organisms are thought to depend on certain environmental (extrinsic) factors to which cells are exposed before they enter the quiescent or senescent state $[24,48,57,58]$. In contrast, the maximum lifespans of organisms across species are considered to rely on certain cellular and organismal longevity modifiers that operate after cells enter the quiescent or senescent state $[48,52,57,58,59]$.

Our data also show that the ability of each of the fifteen longevity-prolonging PEs to decelerate yeast chronological aging correlates with (and is possibly caused by) its ability to elicit a "hormetic" stress response. A characteristic feature of such a response is a nonlinear and biphasic (i. e., inverted U-shaped or J-shaped) doseresponse curve [21, 60-63]. As we found, the curves that reflect relationships between $\mathrm{PE}$ concentrations and mean or maximum yeast CLS are inverted U-shaped or J-shaped for all these PEs (Supplementary Figures 1-6).

\section{Each of the fifteen geroprotective PEs intensifies mitochondrial respiration and alters the pattern of age-related changes in intracellular ROS}

A distinct set of cellular processes is known to define the rate of yeast chronological aging [1, 4, 64-72]. These processes include coupled mitochondrial respiration $[1,4$, 64, 69, 73-77]. We investigated how each of the fifteen geroprotective PEs influences an age-related chronology of changes in coupled mitochondrial respiration, which we measured as the rate of oxygen consumption by yeast cells. We found that each of these PEs causes a statistically significant increase in the rate of mitochondrial respiration
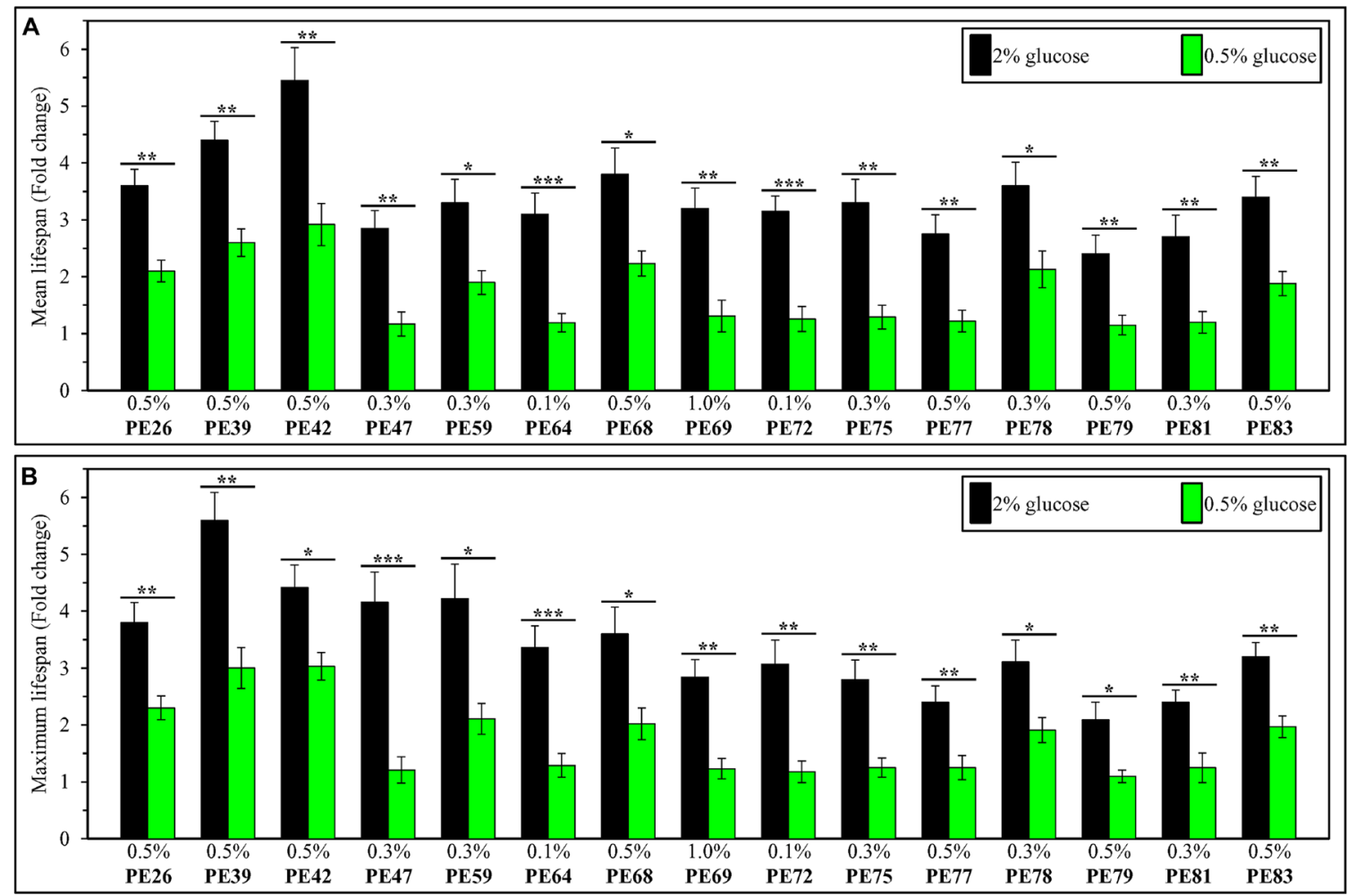

Figure 3: Each of the fifteen PEs extends the longevity of chronologically aging yeast under non-CR conditions on $\mathbf{2 \%}(\mathbf{w} / \mathbf{v})$ glucose significantly more efficiently than it does under CR conditions on $\mathbf{0 . 5 \%}(\mathbf{w} / \mathbf{v})$ glucose. WT cells were cultured in the synthetic minimal YNB medium initially containing $2 \%(\mathrm{w} / \mathrm{v})$ or $0.5 \%(\mathrm{w} / \mathrm{v})$ glucose, in the presence of a PE or its absence. In the cultures supplemented with a PE, ethanol was used as a vehicle at a final concentration of $2.5 \%$ (v/v). In the same experiment, WT cells were also subjected to ethanol-mock treatment by being cultured in the synthetic minimal YNB medium initially containing $0.5 \%$ $(\mathrm{w} / \mathrm{v})$ or $2 \%(\mathrm{w} / \mathrm{v})$ glucose and $2.5 \%(\mathrm{v} / \mathrm{v})$ ethanol. The extent to which each of the PE tested increases the mean (A) and maximum (B) CLS under non-CR and CR conditions was calculated based on the data presented in Figures 1 and 2, and Supplementary Figures 10 and 11. ${ }^{*} p<0.05,{ }^{* *} p<0.01,{ }^{* * *} p<0.001$; the $p$ values for comparing the means of two in groups were calculated using an unpaired two-tailed $t$ test as described in Materials and Methods. 
on days 3 and 4 of culturing in the YNB medium initially containing 2\% (w/v) glucose (Figure 5). On these days of culturing in the YNB medium with $2 \%(\mathrm{w} / \mathrm{v})$ glucose, yeast cells are known to enter and proceed through a stationary (ST) phase of culturing [33].

We found that the fifteen geroprotective PEs belong to two different groups regarding their effects on the agerelated dynamics of changes in coupled mitochondrial respiration under non-CR conditions. The first group of these PEs includes PE47, PE64, PE69, PE72, PE75, PE77, PE79 and PE81. Although all these geroprotective PEs allowed the yeast to maintain the rates of mitochondrial respiration significantly exceeding those in yeast subjected to ethanol-mock treatment, none of them prevented an age-related decline in mitochondrial respiration during the ST phase of culturing (Figure 5D, 5F, 5H-5K, 5M and $5 \mathrm{~N}$ ). Of note, all geroprotective PEs from the first group were able to extend yeast CLS only under non$\mathrm{CR}$ conditions on $2 \%(\mathrm{w} / \mathrm{v})$ glucose (Figures $1 \mathrm{D}, 1 \mathrm{~F}, 1 \mathrm{H}$, $2 \mathrm{~A}, 2 \mathrm{~B}, 2 \mathrm{C}, 2 \mathrm{E}$ and $2 \mathrm{~F}$ ) but not under $\mathrm{CR}$ conditions on $0.5 \%(\mathrm{w} / \mathrm{v})$ glucose (Supplementary Figures 10D, 10F, $10 \mathrm{H}, 11 \mathrm{~A}, 11 \mathrm{~B}, 11 \mathrm{C}, 11 \mathrm{E}$ and $11 \mathrm{~F})$. The second group of geroprotective PEs includes PE26, PE39, PE42, PE59, PE68, PE78 and PE83. These PEs increased the rate of mitochondrial respiration and sustained it high in ST-phase cultures that were recovered on day 4 (Figure 5A, 5B, 5C, 5E, 5G, 5L and 5O). Noteworthy, all geroprotective PEs from the second group were able to extend yeast CLS under both non-CR conditions on $2 \%(\mathrm{w} / \mathrm{v})$ glucose (Figures 1A-1C, 1E, 1G, 2D and 2G) and CR conditions on $0.5 \%(\mathrm{w} / \mathrm{v})$ glucose (Supplementary Figures $10 \mathrm{~A}-10 \mathrm{C}$, $10 \mathrm{E}, 10 \mathrm{G}, 11 \mathrm{D}$ and $11 \mathrm{G})$. As we hypothesized earlier in the text, it is conceivable that the geroprotective PEs from the first group could target only CR-regulated cellular processes (including mitochondrial respiration), whereas the geroprotective PEs from the second group could target both CR-regulated and housekeeping (i.e., not regulated by CR) cellular processes (including mitochondrial respiration).

Several ROS are known to be the primary byproducts of coupled mitochondrial respiration [78-80]. These ROS of mitochondrial origin are known for their essential roles in defining the rate of aging in organisms across species, including $S$. cerevisiae [69, 79-87].

We found that all fifteen geroprotective PEs alter the age-related dynamics of changes in intracellular ROS (Figure 6). Each of these PEs slowed an age-related decline in intracellular ROS on days 3 and 4 of culturing, thus enabling a moderate but statistically significant rise in intracellular ROS during the ST phase (Figure 6). During the post-diauxic (PD) phase on day 2 of culturing, most of the fifteen geroprotective PEs (other than PE69; Figure $6 \mathrm{H}$ ) elicited a modest but statistically decline in intracellular ROS (Figure 6).

Noteworthy, as described below, we found that there are two different groups of geroprotective PEs with respect to their effects on intracellular ROS during the logarithmic (L) phase on day 1 .

PE47, PE64, PE69, PE72, PE75, PE77, PE79 and PE81 did not elicit a substantial change in intracellular ROS during the L phase of culturing on day 1 (Figure 6D, $6 \mathrm{~F}, 6 \mathrm{H}, 6 \mathrm{I}-6 \mathrm{~K}, 6 \mathrm{M}$ and $6 \mathrm{~N})$. All of them extended yeast CLS only under non-CR conditions on $2 \%(\mathrm{w} / \mathrm{v})$ glucose (Figures 1D, 1F, 1H, 2A, 2B, 2C, 2E and 2F) but not under CR conditions on $0.5 \%(\mathrm{w} / \mathrm{v})$ glucose (Supplementary Figures 10D, 10F, 10H, 11A, 11B, 11C, 11E and 11F).

In contrast, PE26, PE39, PE42, PE59, PE68, PE78 and PE83 caused a substantial decline in intracellular ROS during the $\mathrm{L}$ phase of culturing on day 1 (Figure 6A-6C, 6E, 6G, 6L and 6O). All these geroprotective PEs stimulated mitochondrial respiration and sustained it high in ST-phase cultures (Figure 5A-5C, 5E, 5G, 5L and $5 \mathrm{O}$ ). All of them were also capable of prolonging yeast CLS under both non-CR conditions on $2 \%(\mathrm{w} / \mathrm{v})$ glucose (Figures 1A, 1B, 1C, 1E, 1G, 2D and 2G) and CR conditions on $0.5 \%(\mathrm{w} / \mathrm{v})$ glucose (Supplementary Figures $10 \mathrm{~A}-10 \mathrm{C}, 10 \mathrm{E}, 10 \mathrm{G}, 11 \mathrm{D}$ and $11 \mathrm{G})$.

\section{Each of the fifteen geroprotective PEs decreases the extent of age-related oxidative damage to cellular proteins, and many of them slow the aging-associated buildup of oxidatively impaired membrane lipids as well as mitochondrial and nuclear DNA}

An age-related rise in the intracellular ROS above a toxic threshold has been shown to cause oxidative damage to cellular proteins, lipids and nucleic acids [65, 78-80, 84-95]. The aging-associated accumulation of these oxidized macromolecules is one of the essential contributors to the aging process in yeast and other organisms [65, 78-80, 84-95].

Each of the fifteen geroprotective PEs perturbed the age-related chronology of changes in intracellular ROS (see above). Therefore, we investigated whether each of them also influences the aging-associated accumulation of oxidatively impaired proteins, lipids and DNA in yeast cells cultured under non-CR conditions on $2 \%(\mathrm{w} / \mathrm{v})$ glucose.

We found that all fifteen geroprotective PEs elicit a statistically significant decline in the abundance of oxidatively damaged (carbonylated) cellular proteins in ST-phase cultures recovered on day 4 (Figure 7).

We noticed that these geroprotective PEs belong to two different groups regarding their effects on the extent of protein carbonylation in yeast cells taken on day 1,2 or 3 of culturing.

The first group of these PEs includes PE47, PE64, PE69, PE72, PE75, PE77, PE79 and PE81, all of which did not cause a statistically significant decline in the abundance of oxidatively damaged proteins within yeast cells recovered on day 1, 2 or 3 of culturing (Figure 7D, 
7F, 7H-7K, 7M and 7N). All geroprotective PEs from the first group extended yeast CLS only under non-CR conditions on $2 \%(\mathrm{w} / \mathrm{v})$ glucose (Figures $1 \mathrm{D}, 1 \mathrm{~F}, 1 \mathrm{H}, 2 \mathrm{~A}$, $2 \mathrm{~B}, 2 \mathrm{C}, 2 \mathrm{E}$ and $2 \mathrm{~F}$ ) but not under $\mathrm{CR}$ conditions on $0.5 \%$ (w/v) glucose (Supplementary Figures 10D, 10F, 10H, $11 \mathrm{~A}, 11 \mathrm{~B}, 11 \mathrm{C}, 11 \mathrm{E}$ and 11F).

The second group of geroprotective PEs includes PE26, PE39, PE42, PE59, PE68, PE78 and PE83, all of which substantially lowered the abundance of oxidatively damaged proteins in yeast recovered on day 1, 2 or 3 of culturing (Figure 7A-7C, 7E, 7G, 7L and 7O). Only for PE78 and PE83 such effects on protein carbonylation were not statistically significant in yeast taken on day 1 of culturing (Figure 7L and 7O). All geroprotective PEs from the second group increased yeast CLS under both non-CR conditions on $2 \%(\mathrm{w} / \mathrm{v})$ glucose (Figures $1 \mathrm{~A}-1 \mathrm{C}, 1 \mathrm{E}, 1 \mathrm{G}$, $2 \mathrm{D}$ and $2 \mathrm{G})$ and $\mathrm{CR}$ conditions on $0.5 \%(\mathrm{w} / \mathrm{v})$ glucose (Supplementary Figures 10A, 10B, 10C, 10E, 10G, 11D and $11 \mathrm{G})$.

Our analysis of how each of the fifteen geroprotective PEs influences the extent of oxidative damage to membrane lipids revealed that PE26, PE39, PE42, PE47, PE59, PE64, PE68, PE69, PE72, PE75, PE78 and PE83 statistically significantly decrease it in ST-phase cultures recovered on day 4 (Figure $8 \mathrm{~A}-8 \mathrm{~J}, 8 \mathrm{~L}$ and $8 \mathrm{O}$ ). For PE77, PE79 and PE81, a decline in the abundance of oxidatively impaired membrane lipids in yeast cells taken on day 4 of culturing was noticeable but not statistically significant (Figure $8 \mathrm{~K}, 8 \mathrm{M}$ and $8 \mathrm{~N}$ ). We also found that only those of the fifteen geroprotective PEs that extend
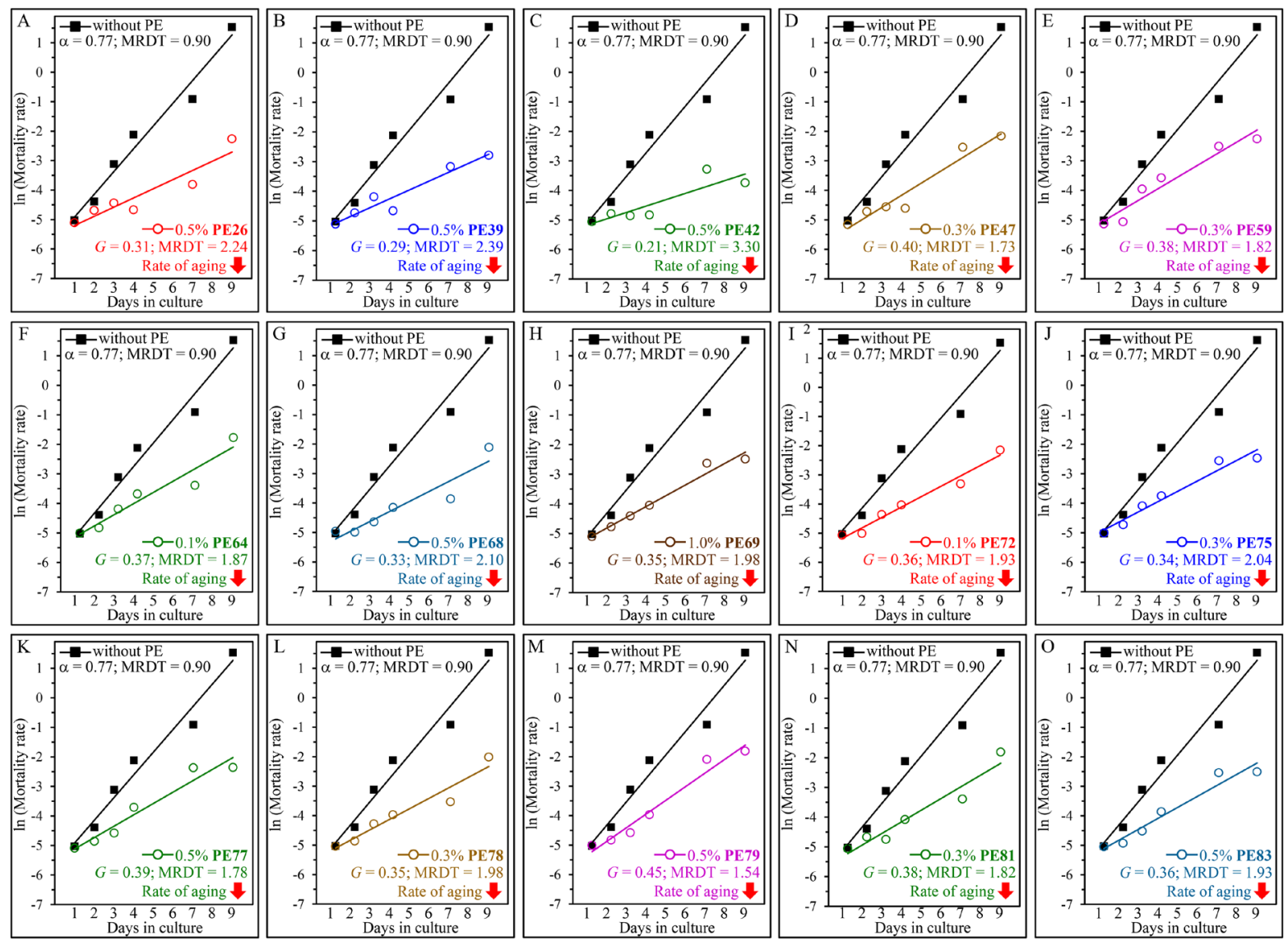

Figure 4: Each of the fifteen PEs extends the longevity of chronologically aging yeast because it decreases the rate of aging but not because it lowers the baseline mortality rate. WT cells were cultured in the synthetic minimal YNB medium initially containing 2\% (w/v) glucose, in the presence of a PE or its absence. The following PEs were added to the culture: $0.5 \%$ (w/v) PE26 (A), 0.5\% (w/v) PE39 (B), 0.5\% (w/v) PE42 (C), 0.3\% (w/v) PE47 (D), 0.3\% (w/v) PE59 (E), 0.1\% (w/v) PE64 (F), $0.5 \%$ (w/v) PE68 (G), $1.0 \%$ (w/v) PE69 (H), 0.1\% (w/v) PE72 (I), $0.3 \%$ (w/v) PE75 (J), 0.5\% (w/v) PE77 (K), $0.3 \%$ (w/v) PE78 (L), $0.5 \%$ (w/v) PE79 (M), $0.3 \%$ (w/v) PE81 $(\mathbf{N})$ or $0.5 \%(\mathrm{w} / \mathrm{v})$ PE83 $(\mathbf{O})$. In the cultures supplemented with a PE, ethanol was used as a vehicle at a final concentration of $2.5 \%$ $(\mathrm{v} / \mathrm{v})$. In the same experiment, WT cells were also subjected to ethanol-mock treatment by being cultured in the synthetic minimal YNB medium initially containing $2 \%(\mathrm{w} / \mathrm{v})$ glucose and $2.5 \%(\mathrm{v} / \mathrm{v})$ ethanol. Survival curves shown in Figures 1 and 2 were used to calculate the age-specific mortality rates of chronologically aging WT yeast populations cultured without a PE (cells were subjected to ethanol-mock treatment) or with a PE (which was added at the concentration optimal for CLS extension). The natural logarithms of the mortality rate values for each time point were plotted against days of cell culturing. The values of the age-specific mortality rates, Gompertz slope (also known as the mortality rate coefficient $G$ ) and mortality rate doubling time (MRDT) were calculated as described in Materials and Methods. Each of the fifteen longevity-extending PEs caused a substantial decline in the value of G and a considerable rise in the value of MRDT. 
yeast CLS under both non-CR and CR conditions significantly lower the abundance of oxidized membrane lipids even in yeast recovered on day 3 of culturing on $2 \%(\mathrm{w} / \mathrm{v})$ glucose (Figure $8 \mathrm{~A}-8 \mathrm{C}, 8 \mathrm{E}, 8 \mathrm{G}, 8 \mathrm{~L}$ and $8 \mathrm{O}$ for PE26, PE39, PE42, PE59, PE68, PE78 and PE83). In contrast, a decline in the abundance of oxidatively damaged membrane lipids on day 3 of culturing on $2 \%(\mathrm{w} / \mathrm{v})$ glucose was noticeable but not statistically significant for any of the geroprotective PEs that increased yeast CLS only under non-CR conditions (Figure $8 \mathrm{D}, 8 \mathrm{~F}$, 8H-8K, 8M and 8N for PE47, PE64, PE69, PE72, PE75, PE77, PE79 and PE81).

We also examined how each of the fifteen geroprotective PEs influences the extent of oxidative damage to mitochondrial DNA (mtDNA) and nuclear DNA (nDNA). The oxidative damage to each of these two types of DNA molecules is known to cause an aging-associated buildup of mutations in mtDNA and nDNA [96-100]. Therefore, we investigated the effect of each of the fifteen geroprotective PEs on the frequencies of spontaneous point mutations in the RIB2 and RIB3 genes of mtDNA [64, 101] as well as the frequencies of spontaneous point mutations in the CAN1 gene of nDNA [64, 101]. We found that all fifteen geroprotective PEs statistically significantly decrease the incidences of rib2 and rib3 mutations in mtDNA of yeast recovered from the ST phase on day 4 but not on any other day of culturing (Figure 9). Furthermore, PE26, PE39, PE42, PE59, PE64, PE69, PE75, PE78, PE79 and PE81 caused a statistically significant decline in the frequencies of can 1 mutations in nDNA of yeast cells that were taken from the ST phase on day 4 of culturing only (Figure 10A-10C, $10 \mathrm{E}, 10 \mathrm{~F}, 10 \mathrm{H}, 10 \mathrm{~J}$ and $10 \mathrm{~L}-10 \mathrm{~N})$. In contrast, neither PE47, PE68, PE72, PE77 nor PE83 elicited a significant change in the incidences of these mutations in nDNA of yeast recovered on any day of culturing (Figure 10D, 10G, 10I, $10 \mathrm{~K}$ and $10 \mathrm{O}$, respectively).
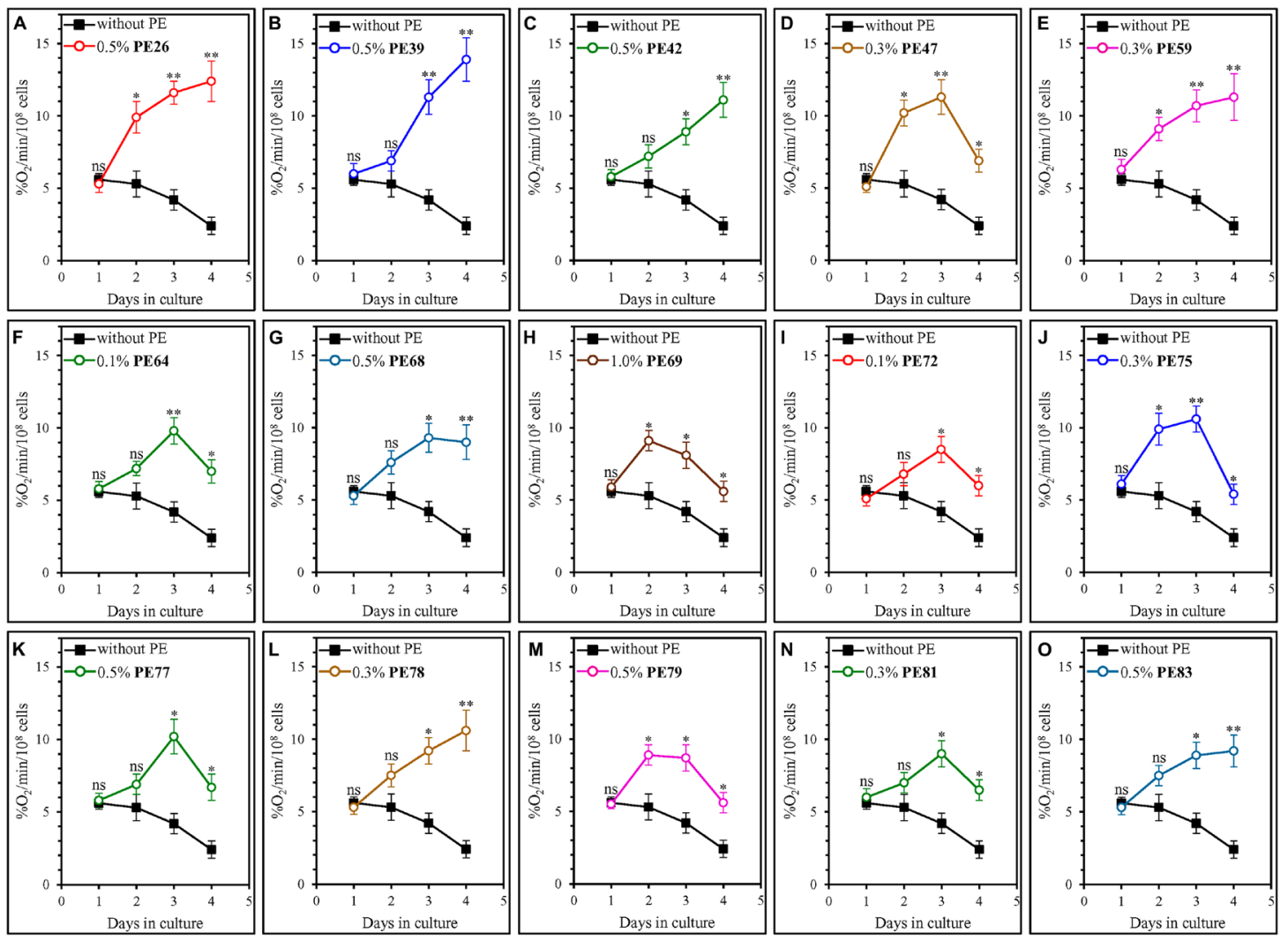

Figure 5: Each of the fifteen geroprotective PEs stimulates mitochondrial respiration in yeast cultured under non-CR conditions. WT cells were cultured in the synthetic minimal YNB medium initially containing $2 \%(\mathrm{w} / \mathrm{v})$ glucose, in the presence of a PE or its absence. The following PEs were added to the culture: $0.5 \%$ (w/v) PE26 (A), $0.5 \%(w / v)$ PE39 (B), $0.5 \%(w / v)$ PE42 (C), $0.3 \%$ (w/v) PE47 (D), 0.3\% (w/v) PE59 (E), 0.1\% (w/v) PE64 (F), 0.5\% (w/v) PE68 (G), 1.0\% (w/v) PE69 (H), 0.1\% (w/v) PE72 (I), 0.3\% (w/v) PE75 (J), 0.5\% (w/v) PE77 (K), 0.3\% (w/v) PE78 (L), 0.5\% (w/v) PE79 (M), 0.3\% (w/v) PE81 (N) or 0.5\% (w/v) PE83 (O). In the cultures supplemented with a PE, ethanol was used as a vehicle at a final concentration of $2.5 \%(\mathrm{v} / \mathrm{v})$. In the same experiment, WT cells were also subjected to ethanol-mock treatment by being cultured in the synthetic minimal YNB medium initially containing $2 \%$ $(\mathrm{w} / \mathrm{v})$ glucose and $2.5 \%(\mathrm{v} / \mathrm{v})$ ethanol. Oxygen uptake by live yeast cells was measured using polarography, as described in Materials and Methods. Age-related changes in the rate of mitochondrial oxygen consumption are shown. Data are presented as means $\pm \operatorname{SEM}\left(n=3 ;{ }^{*} p\right.$ $<0.05,{ }^{* *} p<0.01, n s$, not significant; the $p$ values for comparing the means of two in groups were calculated using an unpaired two-tailed $t$ test as described in Materials and Methods). 


\section{Each of the fifteen geroprotective PEs increases cell resistance to long-term oxidative and thermal stresses}

Genetic, dietary and chemical interventions that decrease cell susceptibility to chronic (long-term) oxidative and/or thermal stresses have been shown to decelerate the aging process and extend longevity in yeast and other organisms across species $[1,4,60-64,78$, 102-106]. Therefore, we investigated the effect of each of the fifteen geroprotective PEs on the susceptibility of chronologically aging yeast cells to these two types of chronic stresses.

To examine aging-associated changes in cell susceptibility to these long-term stresses, we recovered aliquots of yeast cells on days 1,2, 3 and 4 of culturing under non-CR conditions in liquid YNB medium with $2 \%(\mathrm{w} / \mathrm{v})$ glucose. To assess cell susceptibility to chronic oxidative stress, we spotted serial dilutions of these cell aliquots on solid YEP medium with $2 \%(\mathrm{w} / \mathrm{v})$ glucose and $5 \mathrm{mM}$ hydrogen peroxide and incubated them for 3 days. To assess cell susceptibility to chronic thermal stress, we spotted serial dilutions of these cell aliquots on solid YEP medium with $2 \%(\mathrm{w} / \mathrm{v})$ glucose, incubated at $60^{\circ} \mathrm{C}$ for 60 min, transferred the plates to $30^{\circ} \mathrm{C}$ and incubated at this temperature for 3 days.

We found that each of the fifteen geroprotective PEs makes yeast cells more resistant to chronic oxidative and thermal stresses, especially cells in ST-phase cultures recovered on days 3 and 4 (Figure 11A, 11B and 11C, respectively).

\section{DISCUSSION}

We discovered fifteen PEs that extend the longevity of chronologically aging budding yeast. All these PEs
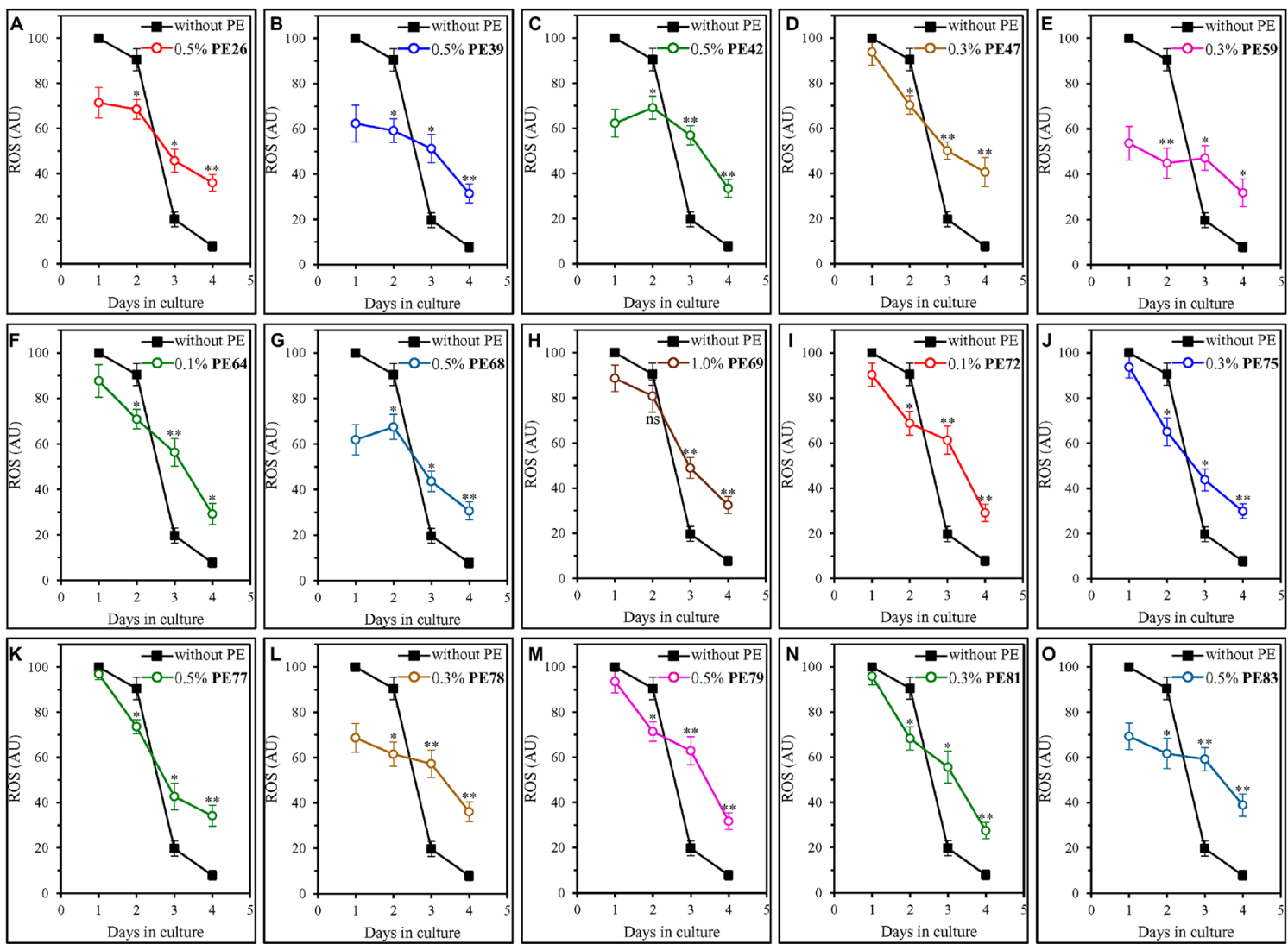

Figure 6: Each of the fifteen geroprotective PEs alters the age-related chronology of changes in intracellular ROS in yeast cultured under non-CR conditions. WT cells were cultured in the synthetic minimal YNB medium initially containing $2 \%$ $(\mathrm{w} / \mathrm{v})$ glucose, in the presence of a PE or its absence. The following PEs were added to the culture: $0.5 \%$ (w/v) PE26 (A), $0.5 \%$ (w/v) PE39 (B), $0.5 \%$ (w/v) PE42 (C), $0.3 \%$ (w/v) PE47 (D), $0.3 \%$ (w/v) PE59 (E), $0.1 \%$ (w/v) PE64 (F), $0.5 \%$ (w/v) PE68 (G), 1.0\% (w/v) PE69 (H), 0.1\% (w/v) PE72 (I), 0.3\% (w/v) PE75 (J), 0.5\% (w/v) PE77 (K), $0.3 \%$ (w/v) PE78 (L), $0.5 \%$ (w/v) PE79 (M), 0.3\% (w/v) PE81 (N) or $0.5 \%(\mathrm{w} / \mathrm{v})$ PE83 (O). In the cultures supplemented with a PE, ethanol was used as a vehicle at a final concentration of $2.5 \%(\mathrm{v} / \mathrm{v})$. In the same experiment, WT cells were also subjected to ethanol-mock treatment by being cultured in the synthetic minimal YNB medium initially containing $2 \%(\mathrm{w} / \mathrm{v})$ glucose and $2.5 \%(\mathrm{v} / \mathrm{v})$ ethanol. The intracellular concentrations of ROS were measured in live yeast by fluorescence microscopy of dihydrorhodamine 123 staining, as described in Materials and Methods. Age-related changes in the intracellular concentration of ROS are shown. Data are presented as means $\pm \operatorname{SEM}\left(n=3 ;{ }^{*} p<0.05,{ }^{* *} p<0.01, n s\right.$, not significant; the $p$ values for comparing the means of two in groups were calculated using an unpaired two-tailed $t$ test as described in Materials and Methods). 
originate from plants used in traditional Chinese and other herbal medicines or the Mediterranean and other longestablished diets. However, none of these PEs has been previously known for its ability to prolong lifespan in yeast or other organisms.

Our data indicate that each of the fifteen longevityextending PEs prolongs yeast CLS not because it slows the metabolism of glucose, the only source of carbon and energy added to the growth medium. We also revealed that the longevity-extending ability of each of the fifteen PEs is not caused by its negative effect on the proliferation of yeast cells. Thus, it seems likely that none of these PEs can prolong yeast CLS because it slows the formation and release of harmful products of cell proliferation.

Our study provides evidence that each of the fifteen longevity-extending PEs satisfies all the criteria previously proposed for a CRM. CRMs are chemical interventions that can mimic the CR-like lifespan-increasing and healthspan-improving effects even if calorie supply is not limited [40-45]. Indeed, we uncovered the following. First, each of the fifteen PEs prolongs yeast CLS under non-CR conditions. Second, none of these PEs impairs glucose uptake and metabolism. Third, each of them exhibits CR-like effects on specific aspects of metabolism and physiology; these effects include an increased rate of coupled mitochondrial respiration, an altered chronology of changes in intracellular ROS, and a decline in the oxidative damage to cellular proteins, membrane lipids and mtDNA. Fourth, each of them makes cells more resistant to long-term oxidative and thermal stresses. Of note, PE26, PE39, PE42, PE59, PE68, PE78 and PE83 can prolong yeast CLS even under CR conditions, when all cellular processes that limit longevity under non-CR conditions are likely to be suppressed. Therefore, it seems conceivable that each of these seven PEs may stimulate the longevity-extending cellular processes and/or may
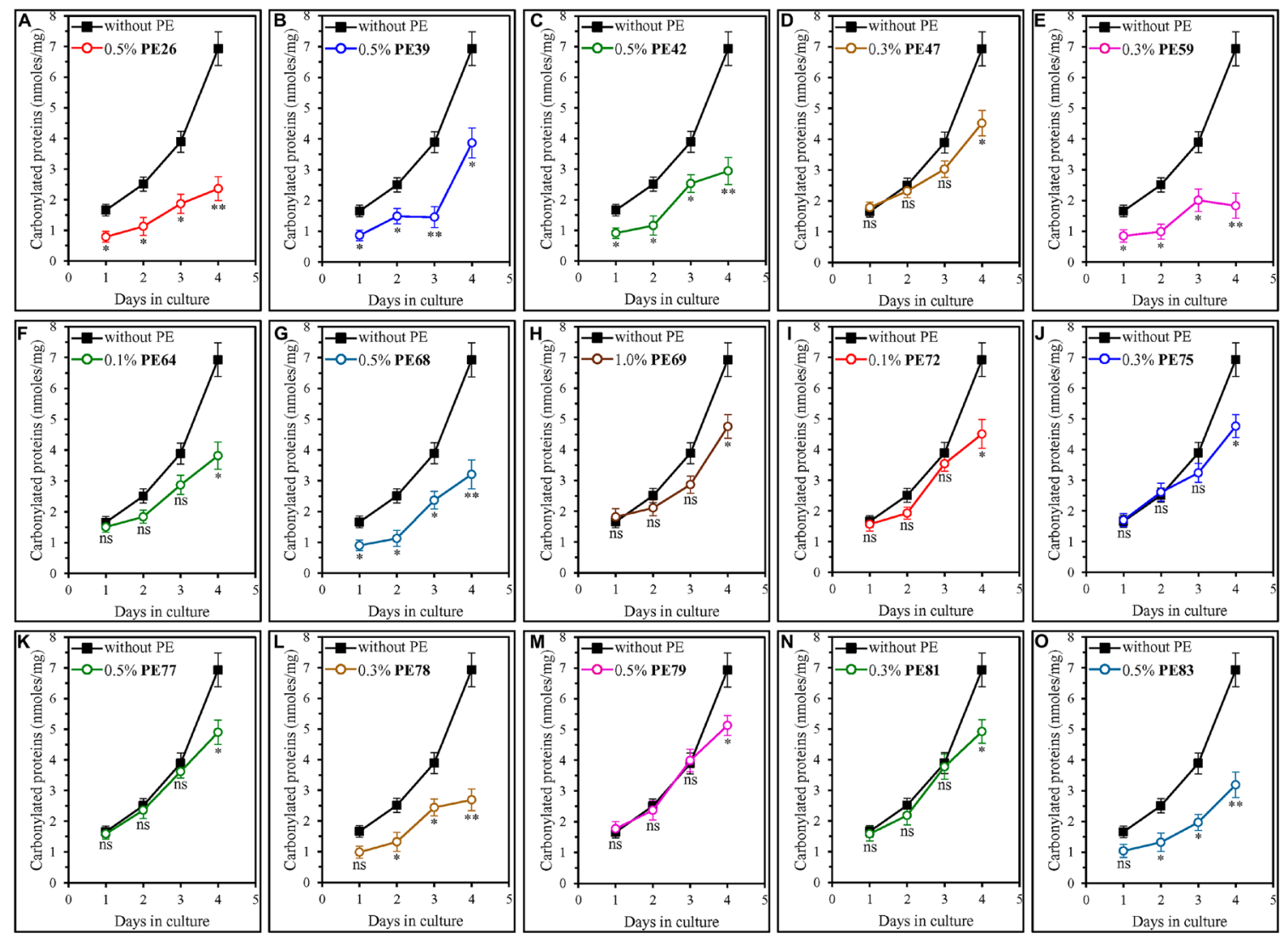

Figure 7: Each of the fifteen geroprotective PEs decreases the extent of age-related oxidative damage to cellular proteins in yeast cultured under non-CR conditions. WT cells were cultured in the synthetic minimal YNB medium initially containing $2 \%(\mathrm{w} / \mathrm{v})$ glucose, in the presence of a PE or its absence. The following PEs were added to the culture: $0.5 \%(\mathrm{w} / \mathrm{v})$ PE26 (A), 0.5\% (w/v) PE39 (B), 0.5\% (w/v) PE42 (C), 0.3\% (w/v) PE47 (D), 0.3\% (w/v) PE59 (E), 0.1\% (w/v) PE64 (F), $0.5 \%$ (w/v) PE68 (G), $1.0 \%$ (w/v) PE69 (H), $0.1 \%$ (w/v) PE72 (I), 0.3\% (w/v) PE75 (J), 0.5\% (w/v) PE77 (K), 0.3\% (w/v) PE78 (L), $0.5 \%$ (w/v) PE79 (M), $0.3 \%$ $(\mathrm{w} / \mathrm{v})$ PE81 (N) or $0.5 \%(\mathrm{w} / \mathrm{v})$ PE83 (O). In the cultures supplemented with a PE, ethanol was used as a vehicle at a final concentration of $2.5 \%(\mathrm{v} / \mathrm{v})$. In the same experiment, WT cells were also subjected to ethanol-mock treatment by being cultured in the synthetic minimal YNB medium initially containing $2 \%(\mathrm{w} / \mathrm{v})$ glucose and $2.5 \%(\mathrm{v} / \mathrm{v})$ ethanol. The concentrations of oxidatively damaged (carbonylated) proteins were measured as described in Materials and Methods. Age-related changes in the intracellular concentration (nmoles/mg protein) of carbonylated proteins are shown. Data are presented as means $\pm \operatorname{SEM}\left(n=3 ;{ }^{*} p<0.05,{ }^{* *} p<0.01, n s\right.$, not significant; the $p$ values for comparing the means of two in groups were calculated using an unpaired two-tailed $t$ test as described in Materials and Methods). 
suppress the longevity-shortening cellular processes that operate only under CR conditions. Moreover, as we hypothesized above in the text, each of these seven PEs may target both CR-regulated and housekeeping (i. e., not regulated by $\mathrm{CR}$ ) cellular processes (including cell susceptibility to long-term oxidative and thermal stresses).

Our analyses of the Gompertz mortality rates and doseresponse curves have led us to the following two conclusions. First, each of the fifteen PEs prolongs yeast CLS because it is a geroprotective agent that decreases the rate of chronological aging but has no effect on the baseline mortality rate. Second, each of these PEs promotes a hormetic stress response in chronologically aging yeast, as it is evident from a nonlinear and biphasic (i. e., inverted U-shaped or J-shaped) doseresponse curve observed for each of them.

In this study, we discovered that the fifteen geroprotective PEs differently affect three groups of cellular processes in chronologically aging yeast, as summarized below.
First, each of the fifteen geroprotective PEs significantly increases the rate of coupled mitochondrial respiration and slows a decline in intracellular ROS (known to be the primary products of mitochondrial respiration) within yeast cells that enter and proceed through the ST phase of culturing.

Second, each of them substantially suppresses oxidative damage to cellular proteins and mtDNA in STphase yeast cells that enter day 4 of culturing. We noticed that twelve of these geroprotective PEs also significantly decrease oxidative damage to membrane lipids in STphase yeast cells on day 4, whereas PE77, PE79 and PE81 cause a statistically insignificant decline in oxidized membrane lipids within these cells. We also found that ten of these geroprotective PEs significantly reduce oxidative damage to nDNA, while neither PE47, PE68, PE72, PE77 nor PE83 exhibits such effect on nDNA.

Third, each of them significantly decreases cell susceptibility to long-term oxidative and thermal stresses,
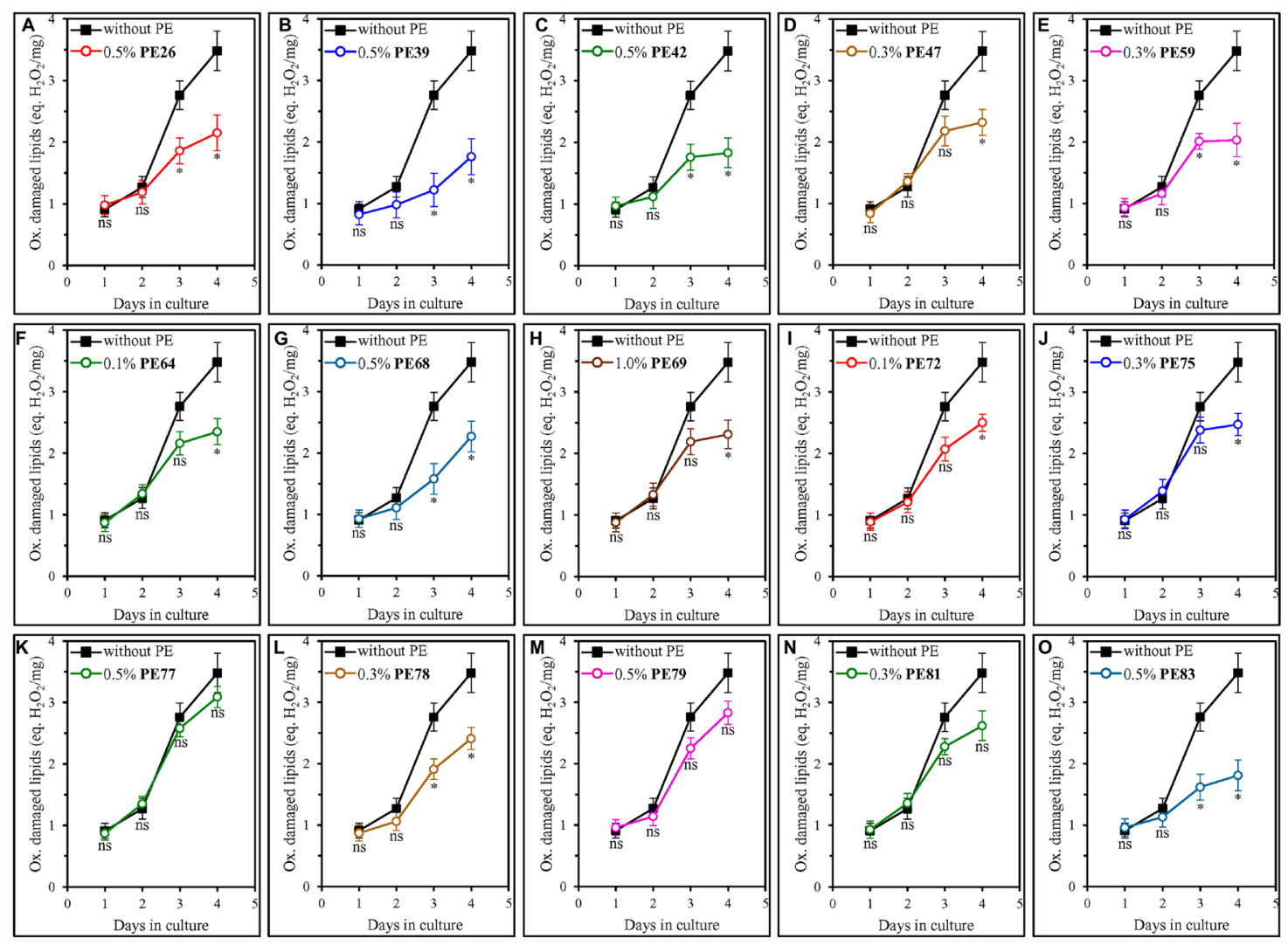

Figure 8: Many of the fifteen geroprotective PEs slow the aging-associated buildup of oxidatively impaired membrane lipids in yeast cultured under non-CR conditions. WT cells were cultured in the synthetic minimal YNB medium initially containing $2 \%(\mathrm{w} / \mathrm{v})$ glucose, in the presence of a PE or its absence. The following PEs were added to the culture: $0.5 \%(\mathrm{w} / \mathrm{v}) \mathrm{PE} 26(\mathbf{A}), 0.5 \%(\mathrm{w} / \mathrm{v})$ PE39 (B), 0.5\% (w/v) PE42 (C), 0.3\% (w/v) PE47 (D), $0.3 \%$ (w/v) PE59 (E), $0.1 \%$ (w/v) PE64 (F), 0.5\% (w/v) PE68 (G), $1.0 \%$ (w/v) PE69 (H), 0.1\% (w/v) PE72 (I), 0.3\% (w/v) PE75 (J), 0.5\% (w/v) PE77 (K), 0.3\% (w/v) PE78 (L), 0.5\% (w/v) PE79 (M), $0.3 \%$ (w/v) PE81 (N) or $0.5 \%(\mathrm{w} / \mathrm{v})$ PE83 (O). In the cultures supplemented with a PE, ethanol was used as a vehicle at a final concentration of $2.5 \%(\mathrm{v} / \mathrm{v})$. In the same experiment, WT cells were also subjected to ethanol-mock treatment by being cultured in the synthetic minimal YNB medium initially containing $2 \%(\mathrm{w} / \mathrm{v})$ glucose and $2.5 \%(\mathrm{v} / \mathrm{v})$ ethanol. The concentrations of oxidatively damaged membrane lipids were measured

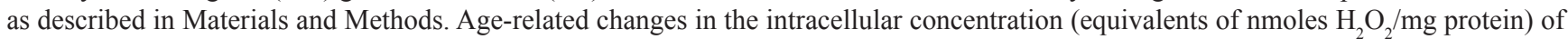
oxidatively damaged membrane lipids are shown. Data are presented as means $\pm \operatorname{SEM}\left(n=3 ;{ }^{*} p<0.05, n s\right.$, not significant; the $p$ values for comparing the means of two in groups were calculated using an unpaired two-tailed $t$ test as described in Materials and Methods). 
especially the susceptibility of yeast cells that enter and proceed through the ST phase of culturing.

\section{Future perspectives}

Our goals for the future research of the fifteen geroprotective PEs described here are outlined below.

First, we are interested in investigating and understanding the molecular and cellular mechanisms through which each of these PEs slows yeast chronological aging. We have recently described mechanisms underlying the aging-delaying action of PE21 [36], an extract from the white willow Salix alba we discovered in our previous screen for geroprotective PEs [33].

Second, we would like to explore how each of the fifteen geroprotective PEs may coordinate the information flow through a longevity-defining network of signaling pathways and protein kinases operating in budding yeast and other organisms. This network incorporates the proaging TORC1, PKA and PKH1/2 pathways as well as the pro-aging serine/threonine-protein kinase Sch9 [1, $4,8,34]$. This network also integrates the anti-aging SNF1 and ATG pathways as well as the anti-aging serine/ threonine-protein kinase Rim15 [1, 4, 8, 34]. Our recent study has revealed that each of the six geroprotective PEs we discovered in the previous screen [33] slows yeast chronological aging through different functional modules of this longevity-defining signaling network [34]. Of note, pairwise mixes of these six geroprotective PEs slow the process of yeast chronological aging in a synergistic or additive manner only if they include the PEs that target different modules of this network [35]. Therefore, we are interested in investigating how different combinations of the fifteen geroprotective PEs described here influence
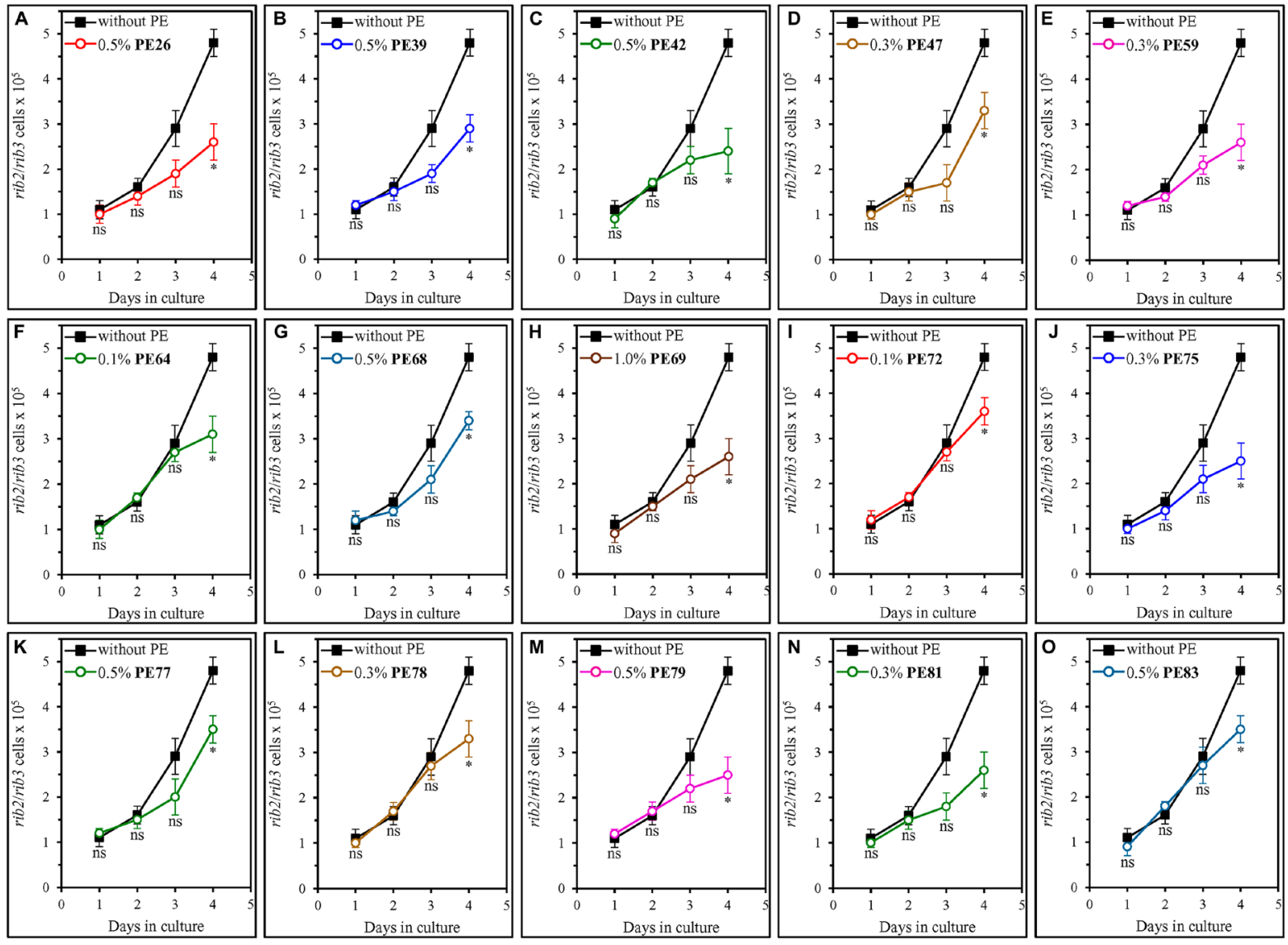

Figure 9: Each of the fifteen geroprotective PEs decreases the frequencies of rib2 and rib3 mutations in mitochondrial DNA (mtDNA) of yeast cultured under non-CR conditions. WT cells were cultured in the synthetic minimal YNB medium initially containing $2 \%(\mathrm{w} / \mathrm{v})$ glucose, in the presence of a PE or its absence. The following PEs were added to the culture: $0.5 \%(\mathrm{w} / \mathrm{v})$ PE26 (A), 0.5\% (w/v) PE39 (B), 0.5\% (w/v) PE42 (C), 0.3\% (w/v) PE47 (D), 0.3\% (w/v) PE59 (E), 0.1\% (w/v) PE64 (F), 0.5\% (w/v) PE68 (G), 1.0\% (w/v) PE69 (H), $0.1 \%$ (w/v) PE72 (I), 0.3\% (w/v) PE75 (J), 0.5\% (w/v) PE77 (K), 0.3\% (w/v) PE78 (L), 0.5\% (w/v) PE79 (M), $0.3 \%$ $(\mathrm{w} / \mathrm{v})$ PE81 (N) or $0.5 \%(\mathrm{w} / \mathrm{v})$ PE83 (O). In the cultures supplemented with a PE, ethanol was used as a vehicle at a final concentration of $2.5 \%(\mathrm{v} / \mathrm{v})$. In the same experiment, WT cells were also subjected to ethanol-mock treatment by being cultured in the synthetic minimal YNB medium initially containing $2 \%(\mathrm{w} / \mathrm{v})$ glucose and $2.5 \%(\mathrm{v} / \mathrm{v})$ ethanol. The incidences of spontaneous point mutations in the RIB2 and RIB3 genes of mtDNA were measured as described in Materials and Methods. Age-related changes in the frequencies of these mtDNA mutations are shown. Data are presented as means $\pm \operatorname{SEM}\left(n=3 ;{ }^{*} p<0.05, n s\right.$, not significant; the $p$ values for comparing the means of two in groups were calculated using an unpaired two-tailed $t$ test as described in Materials and Methods). 
the extent of yeast chronological aging delay. We will be looking for the combinations of geroprotective PEs that exhibit synergistic or additive effects on the extent of yeast chronological aging delay.

Third, the Health Canada government agency defines thirteen of the fifteen geroprotective PEs described here as the ones that are safe for human consumption [107]. The agency recommends using eight of them as health-improving supplements with clinically proven benefits to human health [107]. Among these healthimproving PEs are PE26, PE47, PE59, PE64, PE69, PE75, PE77 and PE83 [107]. For each of them, Health Canada provides a detailed description of source material, routes of administration, doses and dosage forms, uses or purposes, durations of use, risk information, cautions and warnings, contraindications, known adverse reactions, non-medicinal ingredients, specifications, references cited and reviewed, examples of appropriate dosage preparations, and frequencies of use [107]. Our ongoing collaborative research aims to investigate which of the eight geroprotective PEs recommended by Health Canada as healthspan-extending dietary additives for humans can increase the replicative lifespan of cultured human fibroblasts or for delaying the onset of aging-associated human diseases. These diseases include arthritis, diabetes, heart disease, kidney disease, liver dysfunction, sarcopenia, stroke, neurodegenerative diseases (including Parkinson's, Alzheimer's and Huntington's diseases), and many forms of cancer [8, 21, 22, 26, 28, 48, 108-123].

\section{MATERIALS AND METHODS}

\section{Yeast strains, media and growth conditions}

The wild-type (WT) strain Saccharomyces

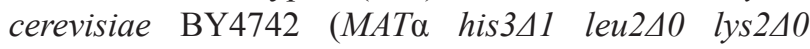
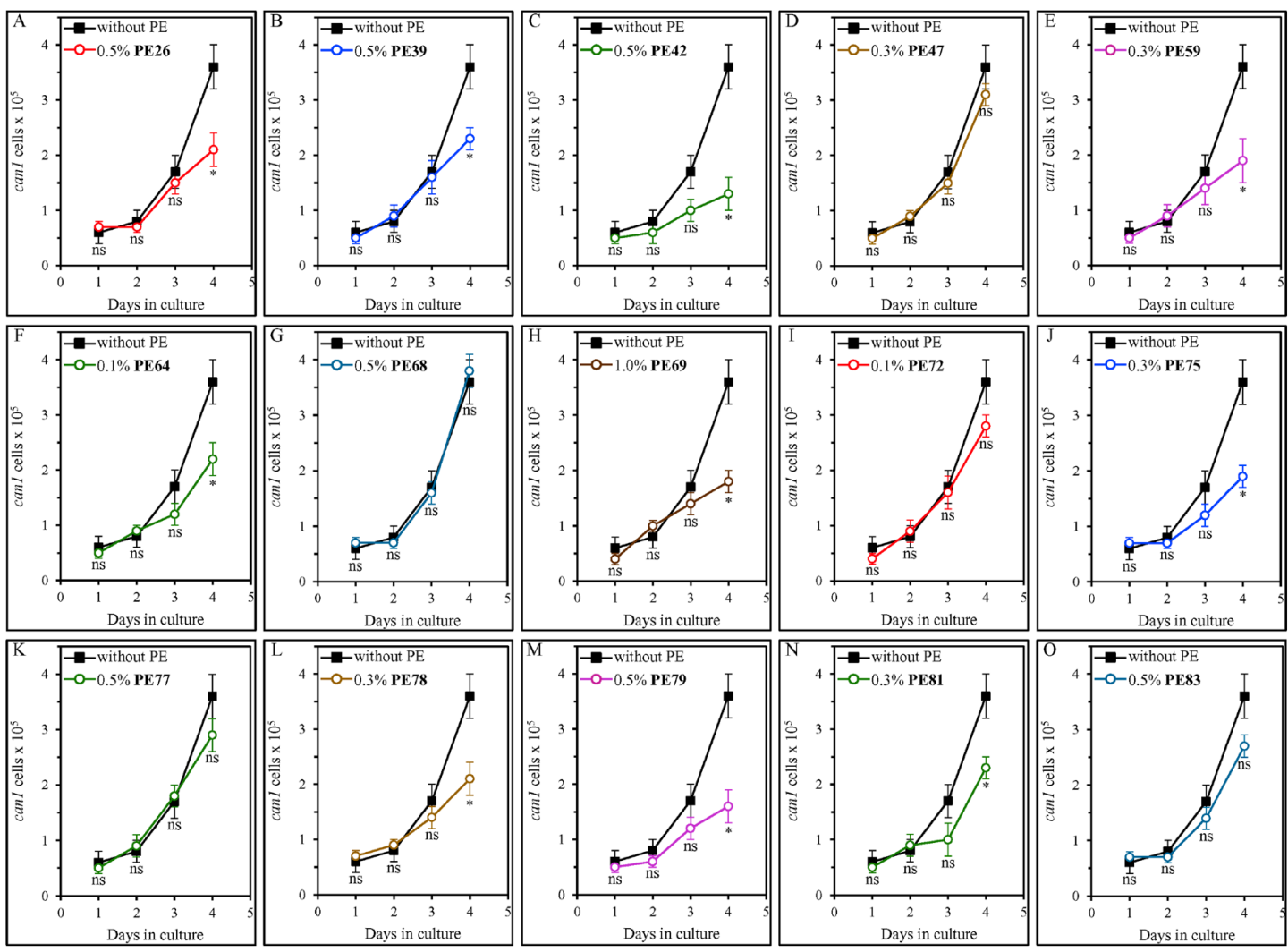

Figure 10: PE26, PE39, PE42, PE59, PE64, PE69, PE75, PE78, PE79 and PE81 (but not PE47, PE68, PE72, PE77 or PE83) cause a statistically significant decline in the frequencies of can1 mutations in nuclear DNA (nDNA) of yeast cultured under non-CR conditions. WT cells were cultured in the synthetic minimal YNB medium initially containing $2 \%$ (w/v) glucose, in the presence of a PE or its absence. The following PEs were added to the culture: 0.5\% (w/v) PE26 (A), $0.5 \%$ (w/v) PE39 (B), $0.5 \%(\mathrm{w} / \mathrm{v})$ PE42 (C), 0.3\% (w/v) PE47 (D), 0.3\% (w/v) PE59 (E), 0.1\% (w/v) PE64 (F), 0.5\% (w/v) PE68 (G), $1.0 \%$ (w/v) PE69 (H), $0.1 \%(w / v)$ PE72 (I), 0.3\% (w/v) PE75 (J), 0.5\% (w/v) PE77 (K), 0.3\% (w/v) PE78 (L), 0.5\% (w/v) PE79 (M), $0.3 \%$ (w/v) PE81 (N) or $0.5 \%(\mathrm{w} / \mathrm{v}) \operatorname{PE} 83(\mathbf{O})$. In the cultures supplemented with a PE, ethanol was used as a vehicle at a final concentration of $2.5 \%(\mathrm{v} / \mathrm{v}) . \mathrm{In}$ the same experiment, WT cells were also subjected to ethanol-mock treatment by being cultured in the synthetic minimal YNB medium initially containing $2 \%(\mathrm{w} / \mathrm{v})$ glucose and $2.5 \%(\mathrm{v} / \mathrm{v})$ ethanol. The incidences of spontaneous point mutations in the CAN1 gene of nDNA were measured as described in Materials and Methods. Age-related changes in the frequencies of these nDNA mutations are shown. Data are presented as means $\pm \operatorname{SEM}\left(n=3 ;{ }^{*} p<0.05, n s\right.$, not significant; the $p$ values for comparing the means of two in groups were calculated using an unpaired two-tailed $t$ test as described in Materials and Methods). 


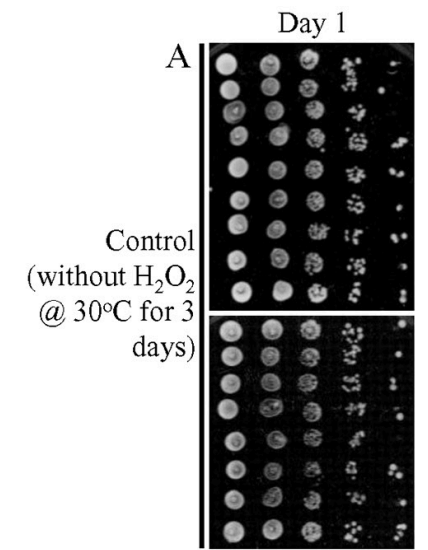

Day 1

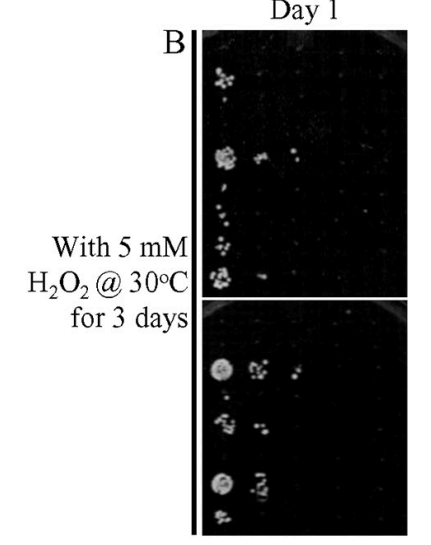

Day 1

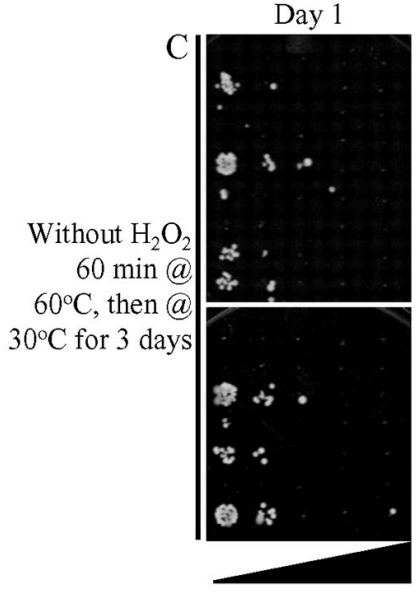

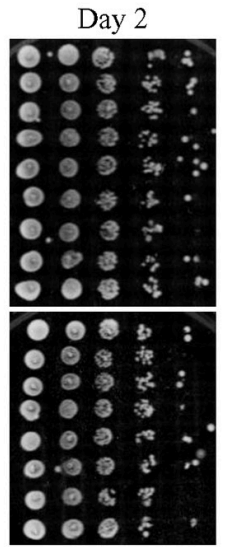

Day 2

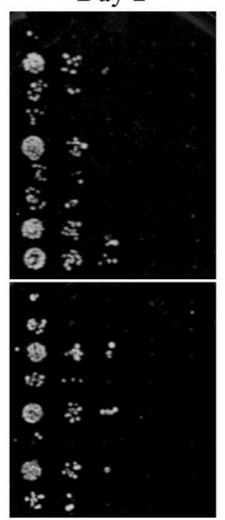

Day 2
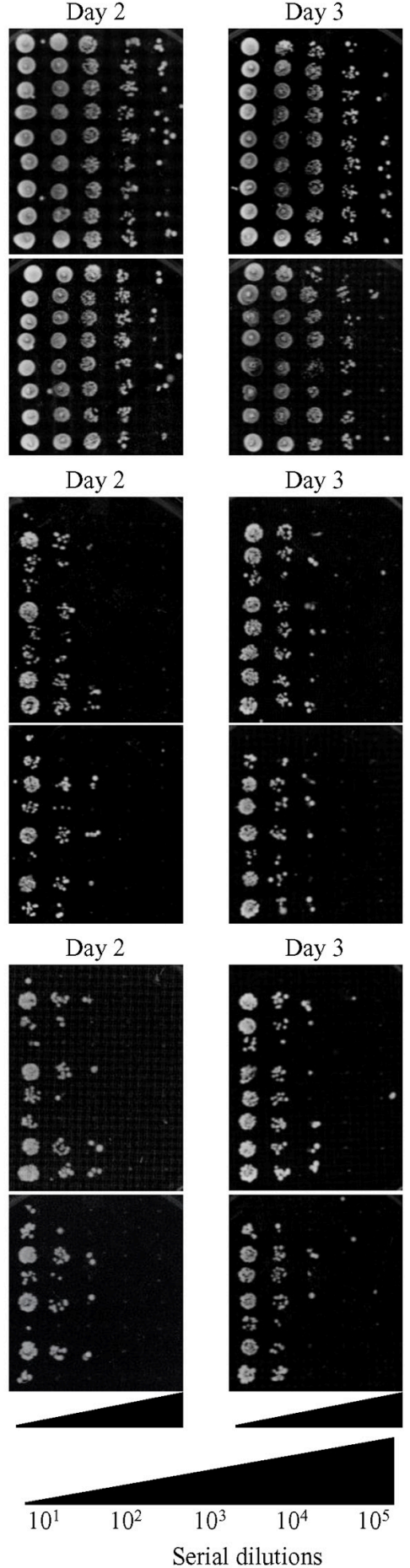

Day 3

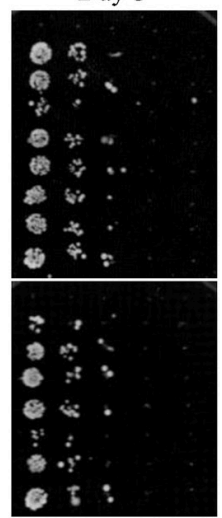

Day 3
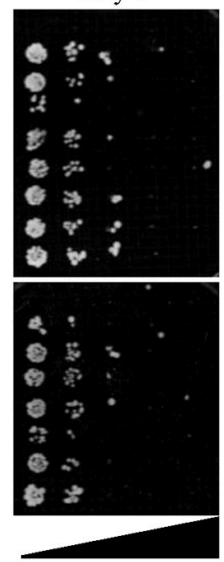

Day 4

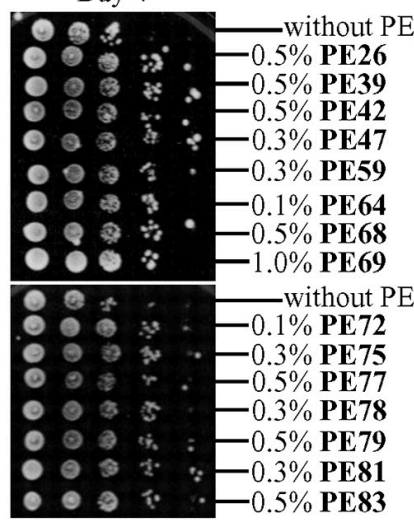

Day 4

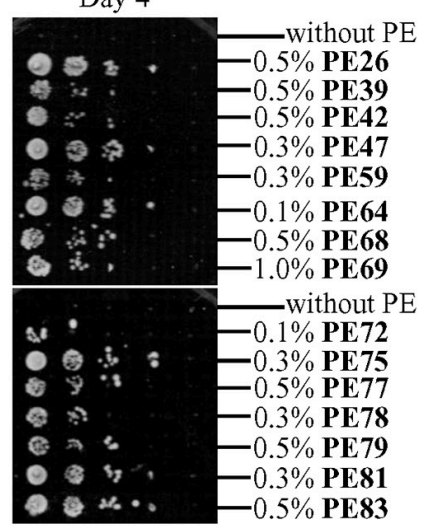

Day 4

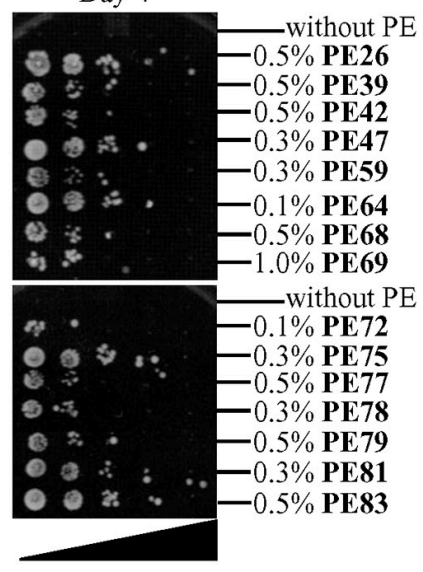

Figure 11: Each of the fifteen geroprotective PEs makes yeast more resistant to chronic (long-term) oxidative and thermal stresses. WT cells were cultured in the synthetic minimal YNB medium initially containing $2 \%(\mathrm{w} / \mathrm{v})$ glucose, in the presence of a PE or its absence. In the cultures supplemented with a PE, ethanol was used as a vehicle at a final concentration of $2.5 \%(\mathrm{v} / \mathrm{v})$. In the same experiment, WT cells were also subjected to ethanol-mock treatment by being cultured in the synthetic minimal YNB medium initially containing $2 \%(\mathrm{w} / \mathrm{v})$ glucose and $2.5 \%(\mathrm{v} / \mathrm{v})$ ethanol. Spot assays for examining cell resistance to chronic oxidative (B) and thermal (C) stresses were performed as described in Materials and Methods. (A) In control samples, serial 10-fold dilutions of cells recovered on different days of culturing were spotted on plates with solid YEP medium containing $2 \%(\mathrm{w} / \mathrm{v})$ glucose. All pictures were taken after a 3-d incubation at $30^{\circ} \mathrm{C}$. (B) In samples subjected to long-term oxidative stress, serial 10 -fold dilutions of cells recovered on different days of culturing were spotted on plates with solid YEP medium containing $2 \%(\mathrm{w} / \mathrm{v})$ glucose and $5 \mathrm{mM}$ hydrogen peroxide. All pictures were taken after a 3-d incubation at $30^{\circ} \mathrm{C}$. (C) In samples subjected to long-term thermal stress, serial 10-fold dilutions of cells recovered on different days of culturing were spotted on plates with solid YEP medium containing $2 \%(\mathrm{w} / \mathrm{v})$ glucose, incubated at $60^{\circ} \mathrm{C}$ for $60 \mathrm{~min}$ and then transferred to $30^{\circ} \mathrm{C}$. All pictures were taken after a 3-d incubation at $30^{\circ} \mathrm{C}$. 
ura3 40 ) from Thermo Scientific/Open Biosystems was grown in a synthetic minimal YNB medium $(0.67 \%(\mathrm{w} / \mathrm{v})$ Yeast Nitrogen Base without amino acids from Fisher Scientific; \#DF0919-15-3) initially containing 2\% (w/v) or $0.5 \%(\mathrm{w} / \mathrm{v})$ glucose (\#D16-10; Fisher Scientific), 20 mg/1 L-histidine (\# H8125; Sigma), 30 mg/l L-leucine (\#L8912; Sigma), 30 mg/l L-lysine (\#L5501; Sigma) and $20 \mathrm{mg} / \mathrm{l}$ uracil (\#U0750; Sigma), with a PE or without it. A stock solution of each PE in ethanol was made on the day of adding this PE to cell cultures. For each PE, the stock solution was added to growth medium with $2 \%(\mathrm{w} / \mathrm{v})$ or $0.5 \%(\mathrm{w} / \mathrm{v})$ glucose immediately following cell inoculation into the medium. In a culture supplemented with a PE, ethanol was used as a vehicle at the final concentration of $2.5 \%(\mathrm{v} / \mathrm{v})$. In the same experiment, yeast cells were also subjected to ethanol-mock treatment by being cultured in growth medium initially containing $2 \%(\mathrm{w} / \mathrm{v})$ or $0.5 \%$ $(\mathrm{w} / \mathrm{v})$ glucose and $2.5 \%(\mathrm{v} / \mathrm{v})$ ethanol. Cells were cultured at $30^{\circ} \mathrm{C}$ with rotational shaking at $200 \mathrm{rpm}$ in Erlenmeyer flasks at a "flask volume/medium volume" ratio of 5:1.

\section{Chronological lifespan assay}

A sample of cells was taken from a culture at a certain day following cell inoculation and PE addition into the medium. A fraction of the sample was diluted to determine the total number of cells using a hemacytometer. Another fraction of the cell sample was diluted, and serial dilutions of cells were plated in duplicate onto YEP medium $(1 \%(\mathrm{w} / \mathrm{v})$ yeast extract, $2 \%(\mathrm{w} / \mathrm{v})$ peptone; both from Fisher Scientific; \#BP1422-2 and \#BP14202 , respectively) containing 2\% (w/v) glucose (\#D16-10; Fisher Scientific) as carbon source. After $2 \mathrm{~d}$ of incubation at $30^{\circ} \mathrm{C}$, the number of colony-forming units (CFU) per plate was counted. The number of CFU was defined as the number of viable cells in a sample. For each culture, the percentage of viable cells was calculated as follows: (number of viable cells per $\mathrm{ml} /$ total number of cells per $\mathrm{ml}) \times 100$. The percentage of viable cells in the midlogarithmic growth phase was set at $100 \%$.

\section{Miscellaneous procedures}

The age-specific mortality rate $[46,48]$, Gompertz slope or mortality rate coefficient $(G)[46,47]$, and mortality rate doubling time (MRDT) [46, 47] were calculated as previously described. The value of the mortality rate was calculated as the number of cells that lost viability (i. e. are unable to form a colony on the surface of a solid nutrient-rich medium) during each time interval divided by the number of viable (i. e. clonogenic) cells at the end of the interval. The natural logarithms of the mortality rate values for each time point were plotted against days of cell culturing. The coefficient $G$ of the age-specific mortality rate was calculated as the slope of the Gompertz mortality line, whereas the value of
MRDT was calculated as $0.693 / G$. Oxygen consumption assay for monitoring mitochondrial respiration [64], ROS measurement in live yeast [124], fluorescence microscopy [64], quantitative assays for oxidatively damaged proteins and membrane lipids [125], measurements of the frequencies of spontaneous mutations in mitochondrial and nuclear DNA [126], plating assays for the analysis of resistance to oxidative and thermal stresses [126], and glucose concentration measurement assay [124] have been described elsewhere.

\section{Statistical analysis}

Statistical analysis was performed using Microsoft Excel's Analysis ToolPack-VBA. All data on cell survival are presented as mean \pm SEM. The $p$ values for comparing the means of two groups using an unpaired two-tailed $t$-test were calculated with the help of the GraphPad Prism 7 statistics software. The logrank test for comparing each pair of survival curves was performed with GraphPad Prism 7. Two survival curves were considered statistically different if the $p$ value was less than 0.05 .

\section{Abbreviations}

ATG1: autophagy protein 1; CLS: chronological lifespan; CR: caloric restriction; CRMs: caloric restriction mimetics; PEs: plant extracts; PKA: protein kinase A; PKH1/2: Pkb-activating kinase homolog proteins 1 and 2; Rim15: a regulator of IME2 protein 15; ROS: reactive oxygen species; SNF1: sucrose non-fermenting protein 1.

\section{ACKNOWLEDGMENTS}

We are grateful to current and former members of the Titorenko laboratory for discussions. We acknowledge the Centre for Structural and Functional Genomics and the Centre for Microscopy and Cellular Imaging (both at Concordia University) for outstanding services.

\section{CONFLICTS OF INTEREST}

Pamela Dakik, Monica Enith Lozano Rodriguez, Jennifer Anne Baratang Junio, Darya Mitrofanova, Younes Medkour, Tala Tafakori, Tarek Taifour, Vicky Lutchman, Eugenie Samson, Anthony Arlia-Ciommo, Belise Rukundo, and Vladimir I. Titorenko have no conflicts of interest to declare. Éric Simard is the president of Idunn Technologies Inc.

\section{FUNDING}

This study was supported by grants from the Natural Sciences and Engineering Research Council of Canada (RGPIN 2014-04482 and CRDPJ 515900 - 
17). Y.M. was supported by the Concordia University Public Scholars Program Award, P.D. by the Concordia University Graduate Fellowship Awards, J.A.B.J. by the Concordia University Merit Award, E.S. by the Concordia Undergraduate Research Award, and A.A-C. by the NSERC Postgraduate Doctoral Scholarship Award.

\section{REFERENCES}

1. Arlia-Ciommo A, Leonov A, Piano A, Svistkova V, Titorenko VI. Cell-autonomous mechanisms of chronological aging in the yeast Saccharomyces cerevisiae. Microb Cell. 2014; 1:163-78. https://doi.org/10.15698/ mic2014.06.152. [PubMed]

2. Denoth Lippuner A, Julou T, Barral Y. Budding yeast as a model organism to study the effects of age. FEMS Microbiol Rev. 2014; 38:300-25. https://doi.org/10.1111/15746976.12060. [PubMed]

3. Kaeberlein M. Lessons on longevity from budding yeast. Nature. 2010; 464:513-19. https://doi.org/10.1038/ nature08981. [PubMed]

4. Longo VD, Shadel GS, Kaeberlein M, Kennedy B. Replicative and chronological aging in Saccharomyces cerevisiae. Cell Metab. 2012; 16:18-31. https://doi. org/10.1016/j.cmet.2012.06.002. [PubMed]

5. Sampaio-Marques B, Burhans WC, Ludovico P. Yeast at the forefront of research on ageing and age-related diseases. Prog Mol Subcell Biol. 2019; 58:217-42. https://doi. org/10.1007/978-3-030-13035-0 9. [ [PubMed]

6. Botstein D, Fink GR. Yeast: an experimental organism for 21st Century biology. Genetics. 2011; 189:695-704. https:// doi.org/10.1534/genetics.111.130765. [PubMed]

7. Feldmann H, editor. Yeast: Molecular and Cell Biology. 2nd ed. Weinheim, Germany: Wiley-Blackwell; 2012. 464 pp. https://doi.org/10.1002/9783527659180.

8. Fontana L, Partridge L, Longo VD. Extending healthy life span - from yeast to humans. Science. 2010; 328:321-26. https://doi.org/10.1126/science.1172539. [PubMed]

9. Smith JS, Burke DJ, editors. Yeast Genetics: Methods and Protocols. New York, USA: Springer; 2014. 378 pp. https:// doi.org/10.1007/978-1-4939-1363-3.

10. Weissman J, Guthrie C, Fink GR, editors. Guide to Yeast Genetics: Functional Genomics, Proteomics, and Other Systems Analysis. Burlington, USA: Academic Press; 2010. 892 pp.

11. Campisi J, Kapahi P, Lithgow GJ, Melov S, Newman JC, Verdin E. From discoveries in ageing research to therapeutics for healthy ageing. Nature. 2019; 571:183-92. https://doi.org/10.1038/s41586-019-1365-2. [PubMed]

12. Campos SE, DeLuna A. Functional genomics of dietary restriction and longevity in yeast. Mech Ageing Dev. 2019; 179:36-43. https://doi.org/10.1016/j.mad.2019.02.003. [PubMed]

13. He C, Zhou C, Kennedy BK. The yeast replicative aging model. Biochim Biophys Acta Mol Basis Dis. 2018; 1864:2690-96. https://doi.org/10.1016/j.bbadis.2018.02.023. [PubMed]
14. Oliveira AV, Vilaça R, Santos CN, Costa V, Menezes R. Exploring the power of yeast to model aging and age-related neurodegenerative disorders. Biogerontology. 2017; 18:334. https://doi.org/10.1007/s10522-016-9666-4. [PubMed]

15. Zimmermann A, Hofer S, Pendl T, Kainz K, Madeo F, Carmona-Gutierrez D. Yeast as a tool to identify anti-aging compounds. FEMS Yeast Res. 2018; 18:foy020. https://doi. org/10.1093/femsyr/foy020. [PubMed]

16. Di Gregorio SE, Duennwald ML. Yeast as a model to study protein misfolding in aged cells. FEMS Yeast Res. 2018; 18:foy054. https://doi.org/10.1093/femsyr/foy054. [PubMed]

17. Eleutherio E, Brasil AA, França MB, de Almeida DS, Rona GB, Magalhães RS. Oxidative stress and aging: learning from yeast lessons. Fungal Biol. 2018; 122:514-25. https:// doi.org/10.1016/j.funbio.2017.12.003. [PubMed]

18. Folch J, Busquets O, Ettcheto M, Sánchez-López E, Pallàs M, Beas-Zarate C, Marin M, Casadesus G, Olloquequi J, Auladell C, Camins A. Experimental models for aging and their potential for novel drug discovery. Curr Neuropharmacol. 2018; 16:1466-83. https://doi.org/10.21 74/1570159X15666170707155345. [PubMed]

19. Fruhmann G, Seynnaeve D, Zheng J, Ven K, Molenberghs S, Wilms T, Liu B, Winderickx J, Franssens V. Yeast buddies helping to unravel the complexity of neurodegenerative disorders. Mech Ageing Dev. 2017; 161:288-305. https:// doi.org/10.1016/j.mad.2016.05.002. [PubMed]

20. Gómez-Linton DR, Alavez S, Alarcón-Aguilar A, LópezDiazguerrero NE, Konigsberg M, Pérez-Flores LJ. Some naturally occurring compounds that increase longevity and stress resistance in model organisms of aging. Biogerontology. 2019; 20:583-603. https://doi.org/10.1007/ s10522-019-09817-2. [PubMed]

21. Leonov A, Arlia-Ciommo A, Piano A, Svistkova V, Lutchman V, Medkour Y, Titorenko VI. Longevity extension by phytochemicals. Molecules. 2015; 20:6544-72. https:// doi.org/10.3390/molecules20046544. [PubMed]

22. Madeo F, Eisenberg T, Pietrocola F, Kroemer G. Spermidine in health and disease. Science. 2018; 359:eaan2788. https:// doi.org/10.1126/science.aan2788. [PubMed]

23. McIsaac RS, Lewis KN, Gibney PA, Buffenstein R. From yeast to human: exploring the comparative biology of methionine restriction in extending eukaryotic life span. Ann N Y Acad Sci. 2016; 1363:155-70. https://doi. org/10.1111/nyas.13032. [PubMed]

24. Medkour Y, Svistkova V, Titorenko VI. Cell-nonautonomous mechanisms underlying cellular and organismal aging. Int Rev Cell Mol Biol. 2016; 321:259-97. https://doi. org/10.1016/bs.ircmb.2015.09.003. [PubMed]

25. Mitchell SJ, Scheibye-Knudsen M, Longo DL, de Cabo R. Animal models of aging research: implications for human aging and age-related diseases. Annu Rev Anim Biosci. 2015; 3:283-303. https://doi.org/10.1146/annurevanimal-022114-110829. [PubMed]

26. Kaeberlein $\mathrm{M}$. The biology of aging: citizen scientists and their pets as a bridge between research on model organisms 
and human subjects. Vet Pathol. 2016; 53:291-98. https:// doi.org/10.1177/0300985815591082. [PubMed]

27. Kumar S, Lombard DB. Finding Ponce de Leon's pill: challenges in screening for anti-aging molecules. F1000Res. 2016; 5:406. https://doi.org/10.12688/f1000research.7821.1. [PubMed]

28. Pitt JN, Kaeberlein M. Why is aging conserved and what can we do about it? PLoS Biol. 2015; 13:e1002131. https:// doi.org/10.1371/journal.pbio.1002131. [PubMed]

29. Ruetenik A, Barrientos A. Exploiting post-mitotic yeast cultures to model neurodegeneration. Front Mol Neurosci. 2018; 11:400. https://doi.org/10.3389/fnmol.2018.00400. [PubMed]

30. Taormina G, Ferrante F, Vieni S, Grassi N, Russo A, Mirisola MG. Longevity: lesson from model organisms. Genes (Basel). 2019; 10:518. https://doi.org/10.3390/ genes10070518. [PubMed]

31. Tenreiro S, Franssens V, Winderickx J, Outeiro TF. Yeast models of Parkinson's disease-associated molecular pathologies. Curr Opin Genet Dev. 2017; 44:74-83. https:// doi.org/10.1016/j.gde.2017.01.013. [PubMed]

32. Verduyckt M, Vignaud H, Bynens T, Van den Brande J, Franssens V, Cullin C, Winderickx J. Yeast as a model for Alzheimer's disease: latest studies and advanced strategies. Methods Mol Biol. 2016; 1303:197-215. https://doi. org/10.1007/978-1-4939-2627-5 11. [PubMed]

33. Lutchman V, Medkour Y, Samson E, Arlia-Ciommo A, Dakik P, Cortes B, Feldman R, Mohtashami S, McAuley M, Chancharoen M, Rukundo B, Simard É, Titorenko VI. Discovery of plant extracts that greatly delay yeast chronological aging and have different effects on longevitydefining cellular processes. Oncotarget. 2016; 7:16542-66. https://doi.org/10.18632/oncotarget.7665. [PubMed]

34. Lutchman V, Dakik P, McAuley M, Cortes B, Ferraye G, Gontmacher L, Graziano D, Moukhariq FZ, Simard É, Titorenko VI. Six plant extracts delay yeast chronological aging through different signaling pathways. Oncotarget. 2016; 7:50845-63. https://doi.org/10.18632/ oncotarget.10689. [PubMed]

35. Dakik P, McAuley M, Chancharoen M, Mitrofanova D, Lozano Rodriguez ME, Baratang Junio JA, Lutchman V, Cortes B, Simard É, Titorenko VI. Pairwise combinations of chemical compounds that delay yeast chronological aging through different signaling pathways display synergistic effects on the extent of aging delay. Oncotarget. 2019; 10:313-38. https://doi.org/10.18632/oncotarget.26553. [PubMed]

36. Medkour Y, Mohammad K, Arlia-Ciommo A, Svistkova V, Dakik P, Mitrofanova D, Rodriguez ME, Junio JA, Taifour T, Escudero P, Goltsios FF, Soodbakhsh S, Maalaoui H, et al. Mechanisms by which PE21, an extract from the white willow Salix alba, delays chronological aging in budding yeast. Oncotarget. 2019; 10:5780-816. https://doi. org/10.18632/oncotarget.27209. [PubMed]
37. Masoro EJ. Overview of caloric restriction and ageing. Mech Ageing Dev. 2005; 126:913-22. https://doi. org/10.1016/j.mad.2005.03.012. [PubMed]

38. Mair W, Dillin A. Aging and survival: the genetics of life span extension by dietary restriction. Annu Rev Biochem. 2008; 77:72754. https://doi.org/10.1146/annurev.biochem.77.061206.171059. [PubMed]

39. Mattison JA, Colman RJ, Beasley TM, Allison DB, Kemnitz JW, Roth GS, Ingram DK, Weindruch R, de Cabo $\mathrm{R}$, Anderson RM. Caloric restriction improves health and survival of rhesus monkeys. Nat Commun. 2017; 8:14063. https://doi.org/10.1038/ncomms14063. [PubMed]

40. Sinclair DA. Toward a unified theory of caloric restriction and longevity regulation. Mech Ageing Dev. 2005; 126:987-1002. https://doi.org/10.1016/j.mad.2005.03.019. [PubMed]

41. Ingram DK, Zhu M, Mamczarz J, Zou S, Lane MA, Roth GS, deCabo R. Calorie restriction mimetics: an emerging research field. Aging Cell. 2006; 5:97-108. https://doi. org/10.1111/j.1474-9726.2006.00202.x. [ubMed]

42. de Magalhães JP, Wuttke D, Wood SH, Plank M, Vora C. Genome-environment interactions that modulate aging: powerful targets for drug discovery. Pharmacol Rev. 2012; 64:88-101. https://doi.org/10.1124/pr.110.004499. [PubMed]

43. Lee SH, Min KJ. Caloric restriction and its mimetics. BMB Rep. 2013; 46:181-87. https://doi.org/10.5483/ BMBRep.2013.46.4.033. [PubMed]

44. Ingram DK, Roth GS. Calorie restriction mimetics: can you have your cake and eat it, too? Ageing Res Rev. 2015; 20:46-62. https://doi.org/10.1016/j.arr.2014.11.005. [PubMed]

45. Lee C, Longo V. Dietary restriction with and without caloric restriction for healthy aging. F1000Res. 2016; 5:F1000 Faculty Rev-117. https://doi.org/10.12688/ f1000research.7136.1. [PubMed]

46. Finch CE. Longevity, senescence, and the genome. Chicago: University of Chicago Press; 1990.

47. de Magalhães JP, Cabral JA, Magalhães D. The influence of genes on the aging process of mice: a statistical assessment of the genetics of aging. Genetics. 2005; 169:265-74. https://doi.org/10.1534/genetics.104.032292. [PubMed]

48. Chapter 1 and 2. In: McDonald RB. Biology of aging. Garland Science, Taylor \& Francis Group, LLC; 2014. pp. 1-54.

49. Kirkwood TB. Deciphering death: a commentary on Gompertz (1825) 'On the nature of the function expressive of the law of human mortality, and on a new mode of determining the value of life contingencies'. Philos Trans R Soc Lond B Biol Sci. 2015; 370:20140379. https://doi. org/10.1098/rstb.2014.0379. [ [PubMed]

50. Creevy KE, Austad SN, Hoffman JM, O’Neill DG, Promislow DE. The Companion Dog as a Model for the Longevity Dividend. In: Olshansky SJ, Martin GM, Kirkland JL, editors. Aging: The Longevity Dividend. Cold 
Spring Harbor (NY): Cold Spring Harbor Laboratory Press; 2016. pp. 107-20.

51. Gavrilov LA, Gavrilova NS. The biology of life span: a quantitative approach. New York, New York/Chur, Switzerland: Harwood Academic; 1991.

52. Fries JF, Bruce B, Chakravarty E. Compression of morbidity 1980-2011: a focused review of paradigms and progress. J Aging Res. 2011; 2011:261702. https://doi. org/10.4061/2011/261702. [PubMed]

53. Promislow DE, Tatar M, Khazaeli AA, Curtsinger JW. Age-specific patterns of genetic variance in Drosophila melanogaster. I. Mortality. Genetics. 1996; 143:839-48. [PubMed]

54. Burger O, Baudisch A, Vaupel JW. Human mortality improvement in evolutionary context. Proc Natl Acad Sci U S A. 2012; 109:18210-14. https://doi.org/10.1073/ pnas.1215627109. [PubMed]

55. Chen J, Senturk D, Wang JL, Müller HG, Carey JR, Caswell $\mathrm{H}$, Caswell-Chen EP. A demographic analysis of the fitness cost of extended longevity in Caenorhabditis elegans. J Gerontol A Biol Sci Med Sci. 2007; 62:126-35. https://doi. org/10.1093/gerona/62.2.126. [PubMed]

56. Lashmanova E, Proshkina E, Zhikrivetskaya S, Shevchenko O, Marusich E, Leonov S, Melerzanov A, Zhavoronkov A, Moskalev A. Fucoxanthin increases lifespan of Drosophila melanogaster and Caenorhabditis elegans. Pharmacol Res. 2015; 100:228-41. https://doi.org/10.1016/j. phrs.2015.08.009. [PubMed]

57. Abrams PA. Evolutionary biology: mortality and lifespan. Nature. 2004; 431:1048-49. https://doi. org/10.1038/4311048a. [PubMed]

58. Kirkwood TB. Understanding the odd science of aging. Cell. 2005; 120:437-47. https://doi.org/10.1016/j. cell.2005.01.027. [PubMed]

59. Blagosklonny MV. Answering the ultimate question "what is the proximal cause of aging?". Aging (Albany NY). 2012; 4:861-77. https://doi.org/10.18632/aging.100525. [PubMed]

60. Goldberg AA, Kyryakov P, Bourque SD, Titorenko VI. Xenohormetic, hormetic and cytostatic selective forces driving longevity at the ecosystemic level. Aging (Albany NY). 2010; 2:461-70. https://doi.org/10.18632/ aging.100186. [PubMed]

61. Calabrese EJ, Mattson MP. Hormesis provides a generalized quantitative estimate of biological plasticity. J Cell Commun Signal. 2011; 5:25-38. https://doi.org/10.1007/ s12079-011-0119-1. [PubMed]

62. Burstein MT, Beach A, Richard VR, Koupaki O, GomezPerez A, Goldberg AA, Kyryakov P, Bourque SD, Glebov A, Titorenko VI. Interspecies chemical signals released into the environment may create xenohormetic, hormetic and cytostatic selective forces that drive the ecosystemic evolution of longevity regulation mechanisms. Dose Response. 2012; 10:75-82. https://doi.org/10.2203/doseresponse.11-011.Titorenko. [PubMed]
63. Calabrese V, Cornelius C, Dinkova-Kostova AT, Iavicoli I, Di Paola R, Koverech A, Cuzzocrea S, Rizzarelli E, Calabrese EJ. Cellular stress responses, hormetic phytochemicals and vitagenes in aging and longevity. Biochim Biophys Acta. 2012; 1822:753-83. https://doi. org/10.1016/j.bbadis.2011.11.002. [PubMed]

64. Goldberg AA, Bourque SD, Kyryakov P, Gregg C, BoukhViner T, Beach A, Burstein MT, Machkalyan G, Richard V, Rampersad S, Cyr D, Milijevic S, Titorenko VI. Effect of calorie restriction on the metabolic history of chronologically aging yeast. Exp Gerontol. 2009; 44:55571. https://doi.org/10.1016/j.exger.2009.06.001. [PubMed]

65. Titorenko VI, Terlecky SR. Peroxisome metabolism and cellular aging. Traffic. 2011; 12:252-59. https://doi. org/10.1111/j.1600-0854.2010.01144.x. [PubMed]

66. Longo VD, Fabrizio P. Chronological aging in Saccharomyces cerevisiae. Subcell Biochem. 2012; 57:101-21. https://doi.org/10.1007/978-94-007-2561-4_5. [PubMed]

67. Piper PW. Maximising the yeast chronological lifespan. Subcell Biochem. 2012; 57:145-59. https://doi. org/10.1007/978-94-007-2561-4_7. [PubMed]

68. Sampaio-Marques B, Burhans WC, Ludovico P. Longevity pathways and maintenance of the proteome: the role of autophagy and mitophagy during yeast ageing. Microb Cell. 2014; 1:118-27. https://doi.org/10.15698/mic2014.04.136. [PubMed]

69. Beach A, Leonov A, Arlia-Ciommo A, Svistkova V, Lutchman V, Titorenko VI. Mechanisms by which different functional states of mitochondria define yeast longevity. Int J Mol Sci. 2015; 16:5528-54. https://doi.org/10.3390/ijms16035528. [PubMed]

70. Medkour Y, Dakik P, McAuley M, Mohammad K, Mitrofanova D, Titorenko VI. Mechanisms underlying the essential role of mitochondrial membrane lipids in yeast chronological aging. Oxid Med Cell Longev. 2017; 2017:2916985. https://doi. org/10.1155/2017/2916985. [PubMed]

71. Mitrofanova D, Dakik P, McAuley M, Medkour Y, Mohammad K, Titorenko VI. Lipid metabolism and transport define longevity of the yeast Saccharomyces cerevisiae. Front Biosci. 2018; 23:1166-94. https://doi. org/10.2741/4638. [PubMed]

72. Banerjee R, Joshi N, Nagotu S. Cell organelles and yeast longevity: an intertwined regulation. Curr Genet. 2020; 66:15-41. https://doi.org/10.1007/s00294-019-01035-0. [PubMed]

73. Bonawitz ND, Chatenay-Lapointe M, Pan Y, Shadel GS. Reduced TOR signaling extends chronological life span via increased respiration and upregulation of mitochondrial gene expression. Cell Metab. 2007; 5:265-77. https://doi. org/10.1016/j.cmet.2007.02.009. [PubMed]

74. Pan Y, Shadel GS. Extension of chronological life span by reduced TOR signaling requires down-regulation of Sch9p and involves increased mitochondrial OXPHOS complex 
density. Aging (Albany NY). 2009; 1:131-45. https://doi. org/10.18632/aging.100016. [PubMed]

75. Pan Y, Schroeder EA, Ocampo A, Barrientos A, Shadel GS. Regulation of yeast chronological life span by TORC1 via adaptive mitochondrial ROS signaling. Cell Metab. 2011; 13:668-78. https://doi.org/10.1016/j.cmet.2011.03.018. [PubMed]

76. Ocampo A, Liu J, Schroeder EA, Shadel GS, Barrientos A. Mitochondrial respiratory thresholds regulate yeast chronological life span and its extension by caloric restriction. Cell Metab. 2012; 16:55-67. https://doi. org/10.1016/j.cmet.2012.05.013. [PubMed]

77. Ruetenik A, Barrientos A. Dietary restriction, mitochondrial function and aging: from yeast to humans. Biochim Biophys Acta. 2015; 1847:1434-47. https://doi.org/10.1016/j. bbabio.2015.05.005. [PubMed]

78. Giorgio M, Trinei M, Migliaccio E, Pelicci PG. Hydrogen peroxide: a metabolic by-product or a common mediator of ageing signals? Nat Rev Mol Cell Biol. 2007; 8:722-28. https://doi.org/10.1038/nrm2240. [PubMed]

79. Ristow M, Schmeisser K. Mitohormesis: promoting health and lifespan by increased levels of reactive oxygen species (ROS). Dose Response. 2014; 12:288-341. https://doi. org/10.2203/dose-response.13-035.Ristow. [PubMed]

80. Zorov DB, Juhaszova M, Sollott SJ. Mitochondrial reactive oxygen species (ROS) and ROS-induced ROS release. Physiol Rev. 2014; 94:909-50. https://doi.org/10.1152/ physrev.00026.2013. [PubMed]

81. Yang W, Hekimi S. A mitochondrial superoxide signal triggers increased longevity in Caenorhabditis elegans. PLoS Biol. 2010; 8:e1000556. https://doi.org/10.1371/ journal.pbio.1000556. [PubMed]

82. Pan Y. Mitochondria, reactive oxygen species, and chronological aging: a message from yeast. Exp Gerontol. 2011; 46:847-52. https://doi.org/10.1016/j.exger.2011.08.007. [PubMed]

83. Yee C, Yang W, Hekimi S. The intrinsic apoptosis pathway mediates the pro-longevity response to mitochondrial ROS in C. elegans. Cell. 2014; 157:897-909. https://doi. org/10.1016/j.cell.2014.02.055. [PubMed]

84. Hekimi S, Wang Y, Noë A. Mitochondrial ROS and the effectors of the intrinsic apoptotic pathway in aging cells: the discerning killers! Front Genet. 2016; 7:161. https://doi. org/10.3389/fgene.2016.00161. [PubMed]

85. Rottenberg H, Hoek JB. The path from mitochondrial ROS to aging runs through the mitochondrial permeability transition pore. Aging Cell. 2017; 16:943-55. https://doi. org/10.1111/acel.12650. [PubMed]

86. Bárcena C, Mayoral P, Quirós PM. Mitohormesis, an antiaging paradigm. Int Rev Cell Mol Biol. 2018; 340:35-77. https://doi.org/10.1016/bs.ircmb.2018.05.002. [PubMed]

87. Giorgi C, Marchi S, Simoes IC, Ren Z, Morciano G, Perrone M, Patalas-Krawczyk P, Borchard S, Jędrak P, Pierzynowska
K, Szymański J, Wang DQ, Portincasa P, et al. Mitochondria and reactive oxygen species in aging and age-related diseases. Int Rev Cell Mol Biol. 2018; 340:209-344. https:// doi.org/10.1016/bs.ircmb.2018.05.006. [PubMed]

88. Beach A, Burstein MT, Richard VR, Leonov A, Levy S, Titorenko VI. Integration of peroxisomes into an endomembrane system that governs cellular aging. Front Physiol. 2012; 3:283. https://doi.org/10.3389/fphys.2012.00283. [PubMed]

89. Cui H, Kong Y, Zhang H. Oxidative stress, mitochondrial dysfunction, and aging. J Signal Transduct. 2012; 2012:646354. https://doi.org/10.1155/2012/646354. [PubMed]

90. Ray PD, Huang BW, Tsuji Y. Reactive oxygen species (ROS) homeostasis and redox regulation in cellular signaling. Cell Signal. 2012; 24:981-90. https://doi. org/10.1016/j.cellsig.2012.01.008. [PubMed]

91. Gladyshev VN. The origin of aging: imperfectness-driven non-random damage defines the aging process and control of lifespan. Trends Genet. 2013; 29:506-12. https://doi. org/10.1016/j.tig.2013.05.004. [PubMed]

92. Gladyshev VN. The free radical theory of aging is dead. Long live the damage theory! Antioxid Redox Signal. 2014; 20:727-31. https://doi.org/10.1089/ars.2013.5228. [PubMed]

93. Schieber M, Chandel NS. ROS function in redox signaling and oxidative stress. Curr Biol. 2014; 24:R453-62. https:// doi.org/10.1016/j.cub.2014.03.034. [PubMed]

94. Shadel GS, Horvath TL. Mitochondrial ROS signaling in organismal homeostasis. Cell. 2015; 163:560-69. https:// doi.org/10.1016/i.cell.2015.10.001. [PubMed]

95. Wang Y, Hekimi S. Mitochondrial dysfunction and longevity in animals: untangling the knot. Science. 2015; 350:120407. https://doi.org/10.1126/science.aac4357. [PubMed]

96. Blasiak J, Glowacki S, Kauppinen A, Kaarniranta K. Mitochondrial and nuclear DNA damage and repair in agerelated macular degeneration. Int J Mol Sci. 2013; 14:29963010. https://doi.org/10.3390/ijms14022996. [PubMed]

97. Santos RX, Correia SC, Zhu X, Smith MA, Moreira PI, Castellani RJ, Nunomura A, Perry G. Mitochondrial DNA oxidative damage and repair in aging and Alzheimer's disease. Antioxid Redox Signal. 2013; 18:2444-57. https:// doi.org/10.1089/ars.2012.5039. [PubMed]

98. Szczepanowska K, Trifunovic A. Different faces of mitochondrial DNA mutators. Biochim Biophys Acta. 2015; 1847:1362-72. https://doi.org/10.1016/j. bbabio.2015.05.016. [PubMed]

99. Nissanka N, Moraes CT. Mitochondrial DNA damage and reactive oxygen species in neurodegenerative disease. FEBS Lett. 2018; 592:728-42. https://doi.org/10.1002/18733468.12956. [PubMed]

100. Kaarniranta K, Pawlowska E, Szczepanska J, Jablkowska A, Blasiak J. Role of mitochondrial DNA damage in ROS-Mediated pathogenesis of age-related macular degeneration (AMD). Int J Mol Sci. 2019; 20:2374. https:// doi.org/10.3390/ijms20102374. [PubMed] 
101. Goldberg AA, Richard VR, Kyryakov P, Bourque SD, Beach A, Burstein MT, Glebov A, Koupaki O, Boukh-Viner T, Gregg C, Juneau M, English AM, Thomas DY, Titorenko VI. Chemical genetic screen identifies lithocholic acid as an anti-aging compound that extends yeast chronological life span in a TOR-independent manner, by modulating housekeeping longevity assurance processes. Aging (Albany NY). 2010; 2:393-414. https://doi.org/10.18632/ aging.100168. [PubMed]

102. D'Autréaux B, Toledano MB. ROS as signalling molecules: mechanisms that generate specificity in ROS homeostasis. Nat Rev Mol Cell Biol. 2007; 8:813-24. https://doi. org/10.1038/nrm2256. [PubMed]

103. Gems D, Partridge L. Stress-response hormesis and aging: "that which does not kill us makes us stronger". Cell Metab. 2008; 7:200-03. https://doi.org/10.1016/j. cmet.2008.01.001. [PubMed]

104. Wei M, Fabrizio P, Hu J, Ge H, Cheng C, Li L, Longo VD. Life span extension by calorie restriction depends on Rim 15 and transcription factors downstream of Ras/PKA, Tor, and Sch9. PLoS Genet. 2008; 4:e13. https://doi.org/10.1371/ journal.pgen.0040013. [PubMed]

105. Calabrese V, Cornelius C, Cuzzocrea S, Iavicoli I, Rizzarelli E, Calabrese EJ. Hormesis, cellular stress response and vitagenes as critical determinants in aging and longevity. Mol Aspects Med. 2011; 32:279-304. https://doi. org/10.1016/j.mam.2011.10.007. [PubMed]

106. Veal E, Day A. Hydrogen peroxide as a signaling molecule. Antioxid Redox Signal. 2011; 15:147-51. https://doi. org/10.1089/ars.2011.3968. [PubMed]

107. Health Canada. http://www.hc-sc.gc.ca/index-eng.php.

108. Blagosklonny MV, Hall MN. Growth and aging: a common molecular mechanism. Aging (Albany NY). 2009; 1:35762. https://doi.org/10.18632/aging.100040. [PubMed]

109. Colman RJ, Anderson RM, Johnson SC, Kastman EK, Kosmatka KJ, Beasley TM, Allison DB, Cruzen C, Simmons HA, Kemnitz JW, Weindruch R. Caloric restriction delays disease onset and mortality in rhesus monkeys. Science. 2009; 325:201-04. https://doi. org/10.1126/science.1173635. [PubMed]

110. Niccoli T, Partridge L. Ageing as a risk factor for disease. Curr Biol. 2012; 22:R741-52. https://doi.org/10.1016/j. cub.2012.07.024. [PubMed]

111. Kaeberlein M. Longevity and aging. F1000Prime Rep. 2013; 5:5. https://doi.org/10.12703/P5-5. [PubMed]

112. López-Otín C, Blasco MA, Partridge L, Serrano M, Kroemer G. The hallmarks of aging. Cell. 2013; 153:1194217. https://doi.org/10.1016/j.cell.2013.05.039. [PubMed]

113. Colman RJ, Beasley TM, Kemnitz JW, Johnson SC, Weindruch R, Anderson RM. Caloric restriction reduces age-related and all-cause mortality in rhesus monkeys. Nat Commun. 2014; 5:3557. https://doi.org/10.1038/ ncomms4557. [PubMed]
114. de Cabo R, Carmona-Gutierrez D, Bernier M, Hall MN, Madeo $F$. The search for antiaging interventions: from elixirs to fasting regimens. Cell. 2014; 157:1515-26. https:// doi.org/10.1016/j.cell.2014.05.031. [PubMed]

115. Gems D. What is an anti-aging treatment? Exp Gerontol. 2014; 58:14-18. https://doi.org/10.1016/j.exger.2014.07.003. [PubMed]

116. Hubbard BP, Sinclair DA. Small molecule SIRT1 activators for the treatment of aging and age-related diseases. Trends Pharmacol Sci. 2014; 35:146-54. https://doi.org/10.1016/j. tips.2013.12.004. [PubMed]

117. Kennedy BK, Berger SL, Brunet A, Campisi J, Cuervo AM, Epel ES, Franceschi C, Lithgow GJ, Morimoto RI, Pessin JE, Rando TA, Richardson A, Schadt EE, et al. Geroscience: linking aging to chronic disease. Cell. 2014; 159:709-13. https://doi.org/10.1016/j.cell.2014.10.039. [PubMed]

118. Kennedy BK, Pennypacker JK. Drugs that modulate aging: the promising yet difficult path ahead. Transl Res. 2014; 163:456-65. https://doi.org/10.1016/j.trs1.2013.11.007. [PubMed]

119. Piano A, Titorenko VI. The intricate interplay between mechanisms underlying aging and cancer. Aging Dis. 2014; 6:56-75. https://doi.org/10.14336/AD.2014.0209. [PubMed]

120. Carvalhal Marques F, Volovik Y, Cohen E. The roles of cellular and organismal aging in the development of lateonset maladies. Annu Rev Pathol. 2015; 10:1-23. https:// doi.org/10.1146/annurev-pathol-012414-040508. [PubMed]

121. Fontana L, Partridge L. Promoting health and longevity through diet: from model organisms to humans. Cell. 2015; 161:106-18. https://doi.org/10.1016/j.cell.2015.02.020. [PubMed]

122. Longo VD, Antebi A, Bartke A, Barzilai N, Brown-Borg HM, Caruso C, Curiel TJ, de Cabo R, Franceschi C, Gems D, Ingram DK, Johnson TE, Kennedy BK, et al. Interventions to slow aging in humans: are we ready? Aging Cell. 2015; 14:497-510. https://doi.org/10.1111/acel.12338. [PubMed]

123. Moskalev A, Chernyagina E, de Magalhães JP, Barardo D, Thoppil H, Shaposhnikov M, Budovsky A, Fraifeld VE, Garazha A, Tsvetkov V, Bronovitsky E, Bogomolov V, Scerbacov A, et al. Geroprotectors.org: a new, structured and curated database of current therapeutic interventions in aging and age-related disease. Aging (Albany NY). 2015; 7:616-28. https://doi.org/10.18632/aging.100799. [PubMed]

124. Kyryakov P, Beach A, Richard VR, Burstein MT, Leonov A, Levy S, Titorenko VI. Caloric restriction extends yeast chronological lifespan by altering a pattern of age-related changes in trehalose concentration. Front Physiol. 2012; 3:256. https://doi.org/10.3389/fphys.2012.00256. [PubMed]

125. Richard VR, Leonov A, Beach A, Burstein MT, Koupaki O, Gomez-Perez A, Levy S, Pluska L, Mattie S, Rafesh R, Iouk T, Sheibani S, Greenwood M, et al. Macromitophagy 
is a longevity assurance process that in chronologically aging yeast limited in calorie supply sustains functional mitochondria and maintains cellular lipid homeostasis. Aging (Albany NY). 2013; 5:234-69. https://doi. org/10.18632/aging.100547. [PubMed]

126. Burstein MT, Kyryakov P, Beach A, Richard VR, Koupaki O, Gomez-Perez A, Leonov A, Levy S, Noohi F, Titorenko
VI. Lithocholic acid extends longevity of chronologically aging yeast only if added at certain critical periods of their lifespan. Cell Cycle. 2012; 11:3443-3462. https://doi. org/10.4161/cc.21754. [PubMed] 